\title{
Adaptation across multiple landscapes: Relatedness, complexity, and the long run effects of coordination in diversified firms
}

\section{Mo Chen ${ }^{1}$ | Aseem Kaul ${ }^{2}$ | Brian $\mathrm{Wu}^{3}$}

${ }^{1}$ Department of Management and Organization, R.H. Smith School of Business, University of Maryland, College Park, Maryland

${ }^{2}$ Strategic Management \& Entrepreneurship Department, Carlson School of Management, University of Minnesota, Minneapolis, Minnesota

${ }^{3}$ Strategy Department, Stephen M. Ross School of Business, University of

Michigan, Ann Arbor, Michigan

\section{Correspondence}

Mo Chen, Department of Management and Organization, R.H. Smith School of Business, University of Maryland, College Park, MD.

Email: mochen@rhsmith.umd.edu

\begin{abstract}
Research Summary: We study the effect of coordination between businesses on the adaptation of diversified firms. Using a simulation-based approach, we show that coordination between businesses limits adaptation, causing the relative performance of diversified firms to decline relative to their focused counterparts over time, with this effect being strongest for moderate levels of relatedness between, and complexity within, businesses. Given complexity, firms diversifying into moderately related businesses may therefore be better off limiting coordination between businesses to a few key activities-if they diversify at all-sacrificing short run synergies for long run flexibility. Our study thus offers a novel argument for conglomerate diversification, while linking work on the costs of coordination in diversified firms to the literature on organizational adaptation.
\end{abstract}

Managerial Summary: While coordination of activities between businesses enables a diversified firm to realize synergies, it may also limit the flexibility of each business to adapt to changing conditions over time. Thus, the very cross-business coordination that gives a diversified firm an advantage relative to its single business competitors in the short run may cause it to fall behind them in the long run. Using a mathematical simulation, we show that this negative effect is strongest for firms coordinating across moderately related businesses with activities that are highly interdependent. Multibusiness firms-especially 
moderately related diversifiers in complex businesses-

may thus be better off coordinating only those activities that yield the greatest synergies, foregoing more marginal synergies in the short run for the sake of long run flexibility.

\section{K E Y W O R D S}

adaptation, complexity, coordination costs, diversification, NK model, relatedness

\section{1 | INTRODUCTION}

The study of coordination costs - the costs of managing multiple business lines within a single firm-is a topic of central importance to corporate strategy research. Building off transaction cost theory (Williamson, 1975, 1985, 1991), scholars have long argued that bureaucratic costs of coordinating between businesses set the limits to corporate diversification (Hill, Hitt, \& Hoskisson, 1992; Nayyar, 1992). Firms will diversify to the point where the marginal synergies from further diversification equal the marginal increase in bureaucratic costs (Jones \& Hill, 1988), and these costs will increase with the interdependence between businesses, so that firms diversifying into related businesses may be better off choosing a more limited scope than unrelated diversifiers (Zhou, 2011). While research in this area has traditionally focused on the short run costs of coordinationincluding bureaucratic costs of communication and information flow (Gulati \& Singh, 1998; Jones \& Hill, 1988; Zhou, 2011), monitoring costs and incentive distortions (Hill et al., 1992; Riordan \& Williamson, 1985; Williamson, 1975, 1985), and comparison costs (Nickerson \& Zenger, 2008; Obloj \& Zenger, 2017)—recent scholarship has also recognized that the coordination of activities between businesses may have consequences for the ability of diversified firms to adapt over time (Rawley, 2010). This work argues that firms operating in multiple businesses may make choices that are optimal for the overall firm but suboptimal for individual businesses, so coordination may impose an additional "cost" in the form of organizational rigidity (de Figueiredo, Rawley, \& Rider, 2015; Natividad \& Rawley, 2016; Rawley, 2010).

In this study, we extend this line of research by theoretically examining how coordination between businesses in diversified firms impacts their adaptation. We argue that coordination of related activities between businesses may increase rigidity within each business, since the business will no longer be free to make changes to that activity based on its needs alone; at the same time, coordination of activities between businesses may also enhance cross-business learning, with knowledge and best practices discovered in one business being shared with another (Miller, Fern, \& Cardinal, 2007; Williams, 2007). The net long-run effect of coordination on the performance of diversified firms thus depends on the relative magnitude of these rigidity and learning effects. Where the rigidity effects dominate the learning effects, the very coordination that enables diversified firms to realize synergies between businesses may also inhibit the adaptation of those businesses over time. Thus, while diversified firms may enjoy a performance advantage relative to their focused counterparts in the short run, this advantage may decline - and potentially turn negative-in the long run. The diversified firm still realizes synergies between businesses, but the benefit of these synergies is 
(partially or wholly) offset by the weaker performance of each business due to its failure to adapt as effectively as its more focused counterparts.

We further argue that the relative magnitude of these rigidity and learning effects, and therefore the net long run effect of coordination between businesses on diversified firm performance, will depend on the relationships between the firm's activities. More specifically, we build on prior work that has highlighted the effect of interdependence within a business - that is, complexity - on organizational adaptation (Gavetti \& Levinthal, 2000; Levinthal, 1997; Siggelkow \& Levinthal, 2003) by examining how complexity within businesses interacts with interdependence between businessesthat is, relatedness - to impact adaptation in diversified firms. First, we expect that coordination between businesses will increase with their relatedness, given the greater potential for synergies, thus increasing both rigidity and cross-business learning in the long run. Second, we argue that complexity will amplify the rigidity effects of coordination, with coordination between businesses constraining not only those activities that are coordinated between businesses, but also those activities that depend on these coordinated activities (Claussen, Kretschmer, \& Stieglitz, 2015). At the same time, increasing complexity may boost the benefits of cross-business learning, as the greater difficulty of adaptation within businesses makes cross-business learning more valuable (Claussen et al., 2015; Siggelkow \& Levinthal, 2003).

We study the joint effect of relatedness and complexity on the performance of diversified firms over time using a simulation-based approach. Specifically, we develop a modified version of the NK model (Levinthal, 1997) in which a diversified firm searches over two landscapes while coordinating choices between them, and compare the performance of this diversified firm to the (combined) performance of two focused firms, each searching on a single landscape. The results from our simulation show that coordination between businesses has a negative long-run effect on a diversified firm's performance relative to that of its single business counterparts - that is, diversified firms face long run coordination costs-with this negative effect having a nonlinear relation with both relatedness and complexity. The negative long run consequences of coordination increase with relatedness, but at a decreasing rate, eventually starting to decline as cross-business learning between highly related businesses becomes increasingly valuable. In the presence of complexity, therefore, coordination between businesses is most harmful for adaptation at moderate levels of relatedness. We also find a nonlinear relationship between these long run negative effects and complexity: modest levels of complexity impose severe constraints on a diversified firm's ability to adapt, but increases in complexity beyond moderate levels have little additional effect.

Having examined the effects of relatedness and complexity on the adaptation of diversified firms, we then extend our analysis to consider the short run synergies (net of bureaucratic costs) from coordination between businesses. Two key findings emerge from this analysis. First, we find that the optimal number of activities between businesses that a diversified firm should coordinate is generally less than the number of related activities (i.e., activities with positive potential synergies) between them, with this gap being greater for more complex businesses. Rather than exploiting every potential synergy, diversified firms may be better off realizing only a handful of the most important synergies between businesses, leaving the rest untapped. In the extreme, firms in complex businesses may be better off not diversifying at all. This is because the loss of potential synergies in the short run is more than compensated for by the long run benefits of superior adaptation. Second, we find that, given complexity, the long run advantage of diversified firms has a curvilinear relationship with relatedness: the performance advantage of moving from low to moderate relatedness is substantially less than that of moving from moderate to high relatedness. 
These findings contribute to corporate strategy research in a number of ways. First, we develop and extend the idea that coordination between businesses in diversified firms may be a source of rigidity, moving beyond recent empirical work that has documented rigidity in diversified firms (Natividad \& Rawley, 2016; Rawley, 2010) to examine how the long run costs of coordination between businesses in diversified firms increase with both relatedness and complexity (Burgelman, Snihur, \& Thomas, 2019). By highlighting the role of complexity in driving rigidity, we not only show that interdependence within businesses may cause the performance of diversified firms to vary in nonlinear ways, we also help connect this work to the broader literature on organizational adaptation in the face of complexity (Aggarwal \& Wu, 2015; Claussen et al., 2015; Ethiraj \& Levinthal, 2004; Levinthal, 1997). Second, we shift the focus from the question of how widely a firm should diversify its portfolio of businesses (Jones \& Hill, 1988; Zhou, 2011) to the question of how deeply it should coordinate within that portfolio. While prior work has focused on the problem of excessive diversification (Markides, 1992, 1995), arguing and showing that diversified firms may underperform if they enter too many businesses (Palich, Cardinal, \& Miller, 2000), our findings point to a problem of excessive coordination, suggesting that diversified firms may underperform if the quest for synergies causes them to coordinate too much between any two businesses. Diversified firms thus face a potential trade-off between maximizing synergies in the short run or maintaining flexibility in the long run. Third, our findings highlight a potential advantage of conglomerate diversification, showing that, in the presence of complexity, diversification into largely unrelated businesses may be no worse - and potentially better-in the long run than diversification into moderately related businesses. They also suggest that firms in highly complex businesses may be better off not diversifying at all. These findings thus extend recent work examining the implications of within business complexity for organizational scope and structure choices (Brahm \& Tarzijan, 2016; Weigelt \& Miller, 2013). Finally, we rigorously model the long run effects of coordination between businesses, considering not only the short run economies of scope and bureaucratic costs from coordinating between businesses, but also the long run rigidity and learning effects of such coordination, thus providing a stronger theoretical foundation for further exploration of questions around the strategy, structure, and performance of diversified firms.

\section{2 | THEORETICAL BACKGROUND}

\section{1 | Relatedness, coordination, and adaptation in diversified firms}

Scholars of strategy and organization have long been interested in the costs of hierarchical governance and the limits they impose on firm scope (Coase, 1937; Penrose, 1959; Williamson, 1975, 1985 , 1991). In particular, prior work has emphasized the role that costs of coordination play in setting the limits to corporate diversification (Jones \& Hill, 1988; Zhou, 2011). While diversified firms may realize economies of scope from sharing resources and capabilities between related businesses (Chatterjee \& Wernerfelt, 1991; Levinthal \& Wu, 2010; Markides \& Williamson, 1994; Miller, 2006; Montgomery \& Wernerfelt, 1988; Rumelt, 1974, 1982; Yao, 1988), the realization of these scope economies will require coordination within the firm's hierarchy (Teece, 1980, 1982), and such coordination will give rise to bureacratic costs (Jones \& Hill, 1988; Williamson, 1975, 1985). Thus, firms should only diversify to the point where the additional synergies from entering a marginal business equal the increase in bureaucratic costs from doing so (Jones \& Hill, 1988); diversification beyond this optimal level will result in declining performance (Markides, 1992, 1995; Palich et al., 2000). Moreover, these bureaucratic costs may vary with both the nature of diversification (Nayyar, 
F I G URE 1 Effects of coordination between businesses in diversified firms

\begin{tabular}{|c|c|c|}
\hline & Short Run & Long Run \\
\hline Benefits & Economies of Scope & Cross-business Learning \\
\hline Costs & Bureaucratic Costs & Rigidity \\
\hline
\end{tabular}

1992) and the structure of the organization (Hill et al., 1992); specifically, they may increase with the extent of relatedness between businesses, with the result that firms diversifying into more related areas may choose a more limited scope (Zhou, 2011). These costs may include the costs of communication and information transfer (Jones \& Hill, 1988; Zhou, 2011), costs of incentive degradation (Hill \& Hoskisson, 1987; Hoskisson, Hitt, \& Hill, 1991, 1993; Riordan \& Williamson, 1985; Williamson, 1985), influence activities (Alonso, Dessein, \& Matouschek, 2008; Milgrom \& Roberts, 1988), and agency (Amihud \& Lev, 1981, 1999; Denis, Denis, \& Sarin, 1997, 1999; Jensen \& Meckling, 1976), costs of inter-unit conflict (Argyres, 1995; Porter, 1985), and comparison costs of envy between units (Larkin, Pierce, \& Gino, 2012; Nickerson \& Zenger, 2008; Obloj \& Zenger, 2017; Rawley \& Simcoe, 2010). As shown in Figure 1, coordination between businesses in a diversified firm thus produces both (intra-temporal ${ }^{1}$ ) economies of scope and bureaucratic costs in the short run, ${ }^{2}$ with firms only choosing to diversify and coordinate across businesses if the former dominates the latter.

In addition to these costs and benefits, which impact diversified firm performance in the short run, coordination between businesses may also have longer run effects. In particular, recent scholarship has highlighted the potential for diversification to increase organizational rigidity (Aggarwal \& Wu, 2015; de Figueiredo et al., 2015; Rawley, 2010). Decisions in individual businesses within diversified firms may be "sublimated to serve the greater good of the overall firm" (Rawley, 2010, p. 873), and this may create barriers to successful adaptation, as the choices firms make to realize economies of scope between businesses constrain their ability to adapt successfully within businesses (Natividad \& Rawley, 2016). ${ }^{3}$ Coordination between businesses, while enabling firms to realize synergies in the short run, may thus compromise the performance of individual businesses, and therefore of the firm as a whole, in the long run.

Coordination across businesses may also produce additional long run benefits for diversified firms. A key advantage of coordination is the potential for businesses to learn from each other over time. Firms that successfully adapt will seek to replicate the outcomes of successful adaptation internally (Nelson \& Winter, 1982; Rivkin, 2001; Zollo \& Winter, 2002) and this may apply not only to replication across similar units within a single business firm, but also to transfer and replication between units of related businesses within a diversified firm (Kim \& Anand, 2018; Miller et al., 2007; Williams, 2007). First, in so far as a resource or capability is shared between businesses in such a firm, any enhancement of that resource or capability through innovation will benefit the

\footnotetext{
${ }^{1}$ Since we are focused on the benefits and costs of coordinating between businesses, we do not consider inter-temporal economies of scope that arise from redeployment across businesses (Helfat \& Eisenhardt, 2004; Levinthal \& Wu, 2010; Sakhartov \& Folta, 2015; 2016) in our analysis.

${ }^{2}$ This does not mean that economies of scope and bureaucratic costs matter only in the short run; only that they are realized relatively soon after coordination starts, and continue as long as coordination continues. In practice, moreover, some economies of scope and bureaucratic costs may take a few periods to be realized, while some of the long run effects of coordination we discuss next may become apparent fairly quickly; the distinction between short and long run in Figure 1 is therefore best thought of as a continuum.

${ }^{3}$ This is not to suggest that diversified firms cannot change their choices in individual businesses, only that when choosing to do so they will need to consider not only the impact on the focal business but also the impact on the related business. To the extent that making a change in one business means sacrificing the (net) synergies between businesses, diversification thus raises the threshold for changes within a business, slowing adaptation.
} 
performance of both businesses. Both businesses may thus enjoy economies of learning (Yao, 1988) as a consequence of coordination between them. Second, a routine or best practice developed in one business may be shared with a related business within the firm. Coordination between businesses may thus allow each business to make discoveries-either jointly for coordinated activities or through knowledge transfer between businesses whose activities are coordinated-it may not have made on its own (Markides \& Williamson, 1994). ${ }^{4}$ In this way, coordination between businesses, while harmful for autonomous adaptation, may be beneficial for cooperative adaptation (Alonso, Dessein, \& Matouschek, 2015; Claussen et al., 2015; Williamson, 1991). Figure 1 shows these two long run effects of coordination in diversified firms: a rigidity effect (which acts as a cost, reducing performance), and a cross-business learning effect (which benefits performance).

Whether coordination benefits or hurts the performance of a diversified firm in the long run depends on which of these effects dominates. Even if the rigidity effect dominates the learning effect-meaning that the net long run effect of coordination is negative-that does not necessarily mean that the diversified firm underperforms focused firms in the long run; only that its relative advantage declines. Since the diversified firm will continue to enjoy the benefits of economies of scope between businesses (net of bureaucratic costs) as a result of coordination, it may still be better off coordinating between businesses in the long run, just not as well off as it was in the short run. Moreover, even if the effect of rigidity were to make a firm underperform its focused counterparts in the long run, the firm may not always correct course, given the adjustment costs of changing coordination (Argyres, Bigelow, \& Nickerson, 2015; Argyres, Mahoney, \& Nickerson, 2019). First, in many cases, the choices firms make regarding coordination may be hard to reverse, given investments in specialized capabilities and ongoing commitments linked to those choices (Ghemawat, 1991). Second, even if the investments linked to the firm's choices are sunk, path dependence may make adjustments to firm capabilities costly in the short run (Lee, 2008; Leonard-Barton, 1992; Levinthal \& March, 1993). A firm that chose to separate activities that were previously coordinated would experience an immediate drop in synergies, but the benefits of better adaptation within each business would take time to accrue, resulting in short-term losses for the firm (Natividad \& Rawley, 2016). Moreover, separating businesses that were previously linked together may prove disruptive, even if the coordination between them was yielding few synergies (Feldman, 2014; Karim \& Kaul, 2015), further lowering short run performance. Third, it may be cognitively challenging to discern that the shortfall in firm performance is a consequence of coordination, especially in the presence of high levels of interdependence within and between businesses (Kaplan \& Henderson, 2005). At any point in time, the firm will be able to clearly observe the contemporaneous benefits of coordination in the form of realized synergies, but may find it hard to discern the gradual decline in its performance in each business as a consequence of coordination.

\section{2 | Role of complexity}

These long run effects of coordination — rigidity and learning — will not only depend on the extent of relatedness (and hence the extent of coordination) between businesses, they may also be moderated by the extent of interdependence between different activities within each business, that is, its complexity (Burgelman et al., 2019; Milgrom \& Roberts, 1995; Porter, 1985; Siggelkow, 2002;

\footnotetext{
${ }^{4}$ Note that neither of these mechanisms of cross-business learning involves taking a resource or capability out of one business and placing it in another; that is, they are benefits of coordination rather than redeployment between businesses. Even though they accrue over the long run, these cross-business learning benefits are thus distinct from inter-temporal economies of scope (Helfat \& Eisenhardt, 2004).
} 
Thompson, 1967; Weigelt \& Miller, 2013). The prior literature has long emphasized the role of complexity in increasing organizational rigidity by causing firms to get stuck at local optima (Gavetti \& Levinthal, 2000; Levinthal, 1997; Rivkin, 2000; Rivkin \& Siggelkow, 2007; Siggelkow \& Levinthal, 2003, 2005), and shown that such interdependence within businesses has implications for firm performance (Lee \& Alnahedh, 2016; Lenox, Rockart, \& Lewin, 2010). It seems only natural to extend the insights from this work to a diversified firm setting.

In order to do so, we conceptualize each business of the firm as a value chain of activities (Helfat \& Raubitschek, 2000; Porter, 1985; Qian, Agarwal, \& Hoetker, 2012)—manufacturing, marketing, R\&D, procurement, etc.- - each supported by a (operational) capability that allows it to perform that activity (Helfat et al., 2007; Helfat \& Winter, 2011). Note that, for our purposes, we think of capabilities quite broadly - to include physical assets and resources, knowledge, and routines, as well as bundles of these together-whatever enables the firm to complete an activity in a reliable and minimally satisfactory manner (Helfat \& Winter, 2011; Winter, 1995). Firms make choices on individual activities by investing in changing or maintaining their capabilities, in an attempt to maximize the performance of the overall firm. Interdependence within businesses refers to relationships between different activities within the same business, meaning that the performance consequences of the firm's choices on one activity are a function of its choice on others. This in turn means that the capabilities associated with these choices may need to be co-specialized (Argyres \& Zenger, 2012; Kaul, 2013; Williamson, 1975). We define the complexity of each business as the number of such interdependencies within it (Weigelt \& Miller, 2013). Similarly, we define the relatedness of any two businesses as the extent of interdependence between them. Interdependence between businesses refers to the potential relationships between corresponding activities in different businesses, meaning that the performance consequences of the firm's choice on the focal activity in one business are similar to that in the other. This in turn means that the firm may benefit from coordinating that activity between businesses, in order to realize economies of scope (Hart \& Holmstrom, 2010; Levinthal \& Wu, 2010; Miller, 2006; Teece, 1980, 1982). Figure 2 provides a simple illustration of this conceptualization for a firm operating in two businesses (A \& B), with three value chain activities (1, 2, and 3) in each business.

The simple representation in Figure 2 points to the ways in which complexity may impact adaptation in diversified firms. On one hand, it suggests that complexity may amplify rigidity (Aggarwal \&

Business A

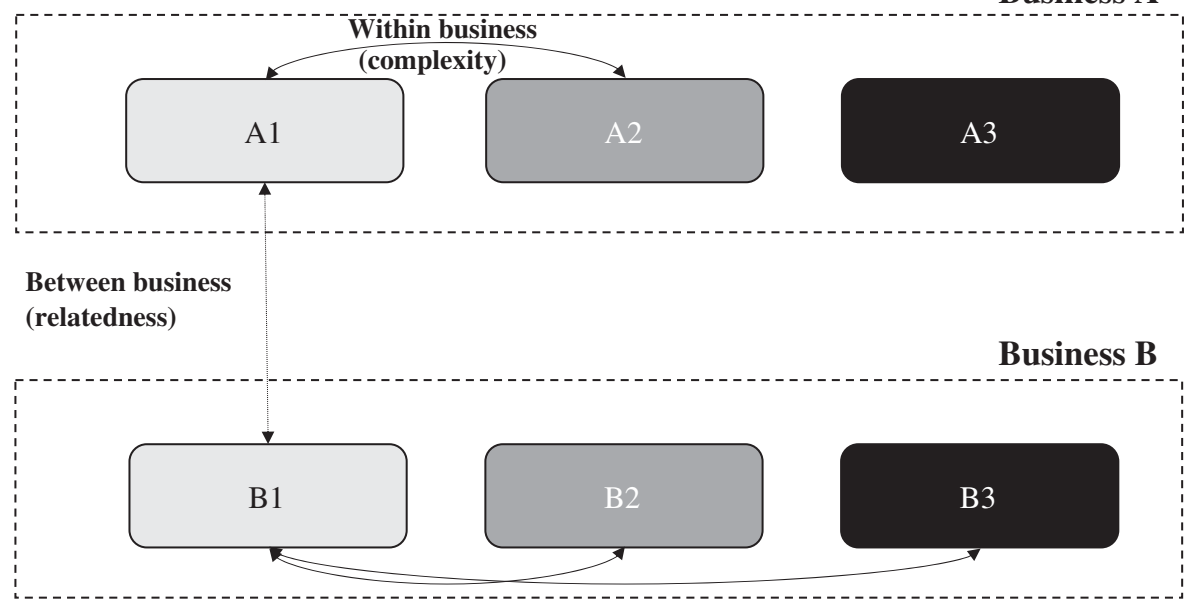

F I G U RE 2 Interdependence within and between businesses 
Wu, 2015; Natividad \& Rawley, 2016; Rawley, 2010). If choices on activities within a business are linked to each other (Porter, 1985; Siggelkow, 2002), then a constraint on any one of those choices potentially serves as a constraint on them all (Kapoor \& Furr, 2015; Wu, Wan, \& Levinthal, 2014). It follows that in a complex setting, coordination between businesses on an activity does not simply constrain the choice on that activity, it impacts the choices on all other activities that are linked to the coordinated activity. For instance, choosing to coordinate activities A1 and B1 between the two businesses in Figure 2 would not only constrain the firm's choices on those two activities, it would also impact choices on activities A2, B2, and B3.

As an example of such amplification of rigidity, consider the case of Motorola's entry into semiconductors, as described in Holbrook, Cohen, Hounshell, and Klepper (2000). While Motorola did not coordinate its technology choices between its new semiconductor business and its legacy business, it did seek to leverage its legacy relationship with the military when entering semiconductors. In particular, Motorola chose to focus on hybrid technologies rather than thin film and monolithic devices because "hybrid technology's reliability, relatively low price, and suitability for its main customer recommended it to Motorola" (Holbrook et al., 2000, p. 1024, italics added). And even when Motorola did eventually pursue more advanced technologies, its attempts to do so were "hampered by its geographic isolation from the new Northern California semiconductor center" and the fact that its "corporate research connections were with companies no longer on the technology frontier" (Holbrook et al., 2000, p. 1024); in other words, by choices-its Phoenix location, its partnership with RCA and Bell Labs - it had made at the behest of the military. Thus, Motorola's technology choices in semiconductors were constrained by its coordination of customer relationships with its other business, even though the technology choices themselves were specific to semiconductors.

On the other hand, complexity may also enhance the benefits of learning across businesses, as increasing complexity makes replication more valuable (Rivkin, 2001). More specifically, coordination between businesses, and the resulting imitation of one business's choices in the other, may benefit the firm in two ways (Csaszar \& Siggelkow, 2010). First, to the extent that the two businesses are similar, the firm may benefit from mimicking combinations of choices between businesses (Csaszar \& Siggelkow, 2010). As complexity increases, finding the optimal combination of choices across activities within a business becomes more challenging (Gavetti \& Levinthal, 2000; Levinthal, 1997), so if a diversified firm is able to transfer the knowledge of how best to combine resources (Helfat \& Raubitschek, 2000; Qian et al., 2012) from one business to another, this may give it an advantage relative to its focused counterparts. Second, diversified firms may benefit from the dislodging effect of coordination on adaptation within each business (Csaszar \& Siggelkow, 2010). As prior work has shown, mechanisms that draw search away from local optima-such as unnecessary linkages between modules (Siggelkow \& Levinthal, 2003), environmental shocks (Claussen et al., 2015), and imperfect imitation (Posen, Lee, \& Yi, 2013) — may prove beneficial in contexts with high complexity. Coordination of activities between businesses may thus serve to dislodge or "scramble" search activities within businesses, resulting in stronger performance.

\section{3 | A SIMULATION-BASED APPROACH}

The preceding discussion suggests that coordination between businesses may either enable or hinder the adaptation of businesses in a diversified firm, and that complexity within businesses may either amplify or ameliorate this effect. The net implications of coordination between businesses in the presence of both relatedness and complexity for the long run performance of diversified firms 
are thus hard to determine using verbal theory alone. We therefore choose to adopt a simulationbased approach to investigate these effects further. Doing so allows us to consider a wide range of values for key underlying drivers, while controlling for other factors that may impact the performance of diversified firms. We are thus able to clearly isolate the effect of coordination between businesses on long run firm performance, as well as the moderating effect of complexity on this main effect. We are also able to consider a full range of potential values of complexity within and relatedness between businesses in a way that would be hard to do empirically. ${ }^{5}$ Moreover, a simulation-based approach allows us to formally explore the combined effect of multiple factors that may drive diversified firm adaptation in a systematic way, thus enabling more rigorous development of theory. Finally, using a simulation allows us to build on and connect with prior theoretical work that has explored adaptation in single business firms (Ethiraj \& Levinthal, 2004; Gavetti \& Levinthal, 2000; Levinthal, 1997).

\section{1 | Multiple landscapes and business relatedness}

In order to model adaptation in diversified firms, we start with the basic NK landscape set-up used in prior work (Levinthal, 1997; Rivkin \& Siggelkow, 2007), that is, we model a firm searching on a landscape of $N=12$ binary choices with the outcome of each choice depending upon the value of $K$ other choices, where $0 \leq K<N$ is thus a parameter reflecting the complexity of the business (details of the NK model framework we use can be found in online Appendix A). We adopt this set-up because it is the canonical simulation model for studying firm adaptation in the face of complexity and has been widely used for this purpose in the prior literature (Claussen et al., 2015; Ethiraj \& Levinthal, 2004; Levinthal, 1997; Siggelkow \& Levinthal, 2003; Sorenson, 2003).

Since we are interested in studying adaptation in diversified firms, however, we modify this set-up by including not one but two landscapes. Specifically, we consider two related NK landscapes of the same structure, without loss of generality. To model relatedness, we utilize a parameter $R$ which captures the number of elements that have similar contribution functions in both landscapes (Csaszar \& Siggelkow, 2010), with $R$ taking values between 0 and $N$. This reflects the idea that relatedness will mean similarity of activities between businesses, so that choices that work well in one business will also work well in the other. Rather than assume that all $R$ activities are exactly the same across landscapes, we model a sliding scale of similarity, with the first element being the most similar across landscapes, the second less similar, and so on. ${ }^{6}$ More specifically, for any value of $R$, we assume the contribution function for the $i$ th element of the second landscape is given by $\alpha c+(1-\alpha) c^{\prime}$ where $c$ is the contribution of the $i$ th element of the first landscape, $c^{\prime}$ is the contribution of the $i$ th element of a randomly generated alternate landscape with same value of $N$ and $K$ as the first landscape, and $\alpha=1-\frac{i-1}{R}$ for $0<i \leq R ; 0$ for $R<i \leq N$. When $R$ is zero, the two businesses are independent, and there is no relationship between the performance of any elements across the two landscapes. As relatedness increases, the landscapes start to

\footnotetext{
${ }^{5}$ It may be the case, for instance, that relatedness and complexity are negatively correlated in practice, with businesses that are more complex being less likely to be closely related to other businesses. If such a correlation existed, it would make it difficult to empirically separate the effects of relatedness and complexity, even though they are conceptually orthogonal. One advantage of the simulation is that it allows us to consider the full range of possible values of our parameters of interest, without having to assume, or being limited by, a relation between them.

${ }^{6}$ For simplicity, and without loss of generality, we assume that the elements are arranged in the order of decreasing relatedness.
} 
look more similar. For parsimony, we assume that both landscapes have the same $K$, that is, they are both equally complex. ${ }^{7}$

\section{2 | Local search}

Consistent with prior work (Levinthal, 1997), we model firms as boundedly rational actors (Simon, 1947), undertaking local search on these landscapes, that is, evaluating alternatives adjacent to their current position, and choosing the first alternative that has better performance. Specifically, it means that firms search by randomly changing exactly one element of their current configuration. If the performance of the new configuration is superior to that of their existing configuration then the new configuration is adopted; if not, then the current configuration is retained, and the firm tries a different alternative in the next period. Search ends where all local alternatives have been evaluated, and none of them has a higher performance.

For diversified firms, this procedure is modified in that instead of searching on one landscape the firm searches on both landscapes simultaneously. The search process continues to be local, in that the firm evaluates changes in one element at a time. ${ }^{8}$ However, we assume that the decisions between the two landscapes are coordinated; specifically, we define a parameter $L$ of the extent of this coordination, such that the choices on the first $L$ elements have to be consistent, that is, if the firm changes one of the $L$ elements on one landscape, it has to simultaneously change the same element on the other landscape as well. This assumption reflects the need for coordination in order for the potential synergies between businesses to be realized (Hart \& Holmstrom, 2010; Zhou, 2011). We begin by considering the case where the firm coordinates all related activities, that is, $L=R$, though we relax this assumption later in our analysis. ${ }^{9}$

\section{3 | Synergies}

To model synergies, we introduce a parameter $\delta \geq 0$, which captures the net short run synergies from coordinating activities between businesses for the diversified firm, that is, it captures the economies of scope from the sharing of capabilities (Levinthal \& Wu, 2010; Montgomery \& Wernerfelt, 1988; Rumelt, 1974; Yao, 1988) less bureacratic costs (Jones \& Hill, 1988; Williamson, 1985). ${ }^{10}$ Specifically, we assume that the firm realizes synergies equal to $\delta \alpha c$ for every element $i$ it coordinates (i.e., every $i \leq L$ ), and only for those elements, consistent with our

\footnotetext{
${ }^{7} \mathrm{We}$ also assume that the structure of interdependence is the same across both businesses, though as we discuss later, our results are robust to relaxing this assumption. Note also that this assumption does not mean that the actual interdependence is the same across businesses. Because of the way we model contribution functions, the payoffs from the same choices in different businesses are different. We are only assuming that the same sets of activities that are interdependent in one business are also interdependent in the other; the extent of their interdependence still varies.

${ }^{8}$ To avoid giving the focused firms a substantial processing power advantage-letting them make two decisions for every one the diversified firm makes - we allow the diversified firm to make two choices for every one made by each focused firm. Note that this does not impact the steady state that the firms achieve, which is what we are principally concerned with in our analyses.

${ }^{9}$ In general, we assume that $L \leq R$, that is, a firm will not coordinate activities unless they are (at least somewhat) similar. This follows logically from the assumption that coordinating unrelated activities produces no synergistic benefits ( $\alpha=0$ for $R<i \leq N)$; in the absence of such benefits, it makes no sense for the firm to constrain itself by coordinating unrelated activities between businesses.

${ }^{10}$ We assume that $\delta \geq 0$, that is, coordination costs are not greater than economies of scope. If this were not the case, the firm would have no incentive to diversify in the first place. Put differently, we assume that a firm will only coordinate activities between businesses if the economies of scope from doing so are equal to or greater than the resulting coordination costs. This
} 
assumption that coordination is necessary to realize synergies. This implies that the extent of synergies realized is proportional to the similarity between the activities in the two landscapes; the logic being that the extent to which the firm can share capabilities related to that activity between the two businesses (and therefore the extent to which it can realize economies of scope) is limited by the extent of similarity between the activities. ${ }^{11}$ For the purposes of our analysis, we examine values of $\delta=0, \frac{1}{2 N}, \frac{1}{N}, \frac{3}{2 N}$ as reflecting reasonable levels of net synergies. ${ }^{12}$ With high enough synergies diversification is always the dominant choice; we therefore confine our analysis to a range of parameter values where the net short run synergies and long run effects of coordination are potentially comparable in magnitude.

\section{4 | Diversified firm advantage}

We compute the performance advantage of a diversified firm by comparing its performance to that of two single business firms. ${ }^{13}$ Specifically, we calculate diversification advantage as the difference between a diversified firm's performance and the combined performance of two equivalent single business firms independently searching on each landscape, as a proportion of the focused firms' performance. Our approach is thus analytically similar to the "chop-shop" approach used in the diversification discount literature (Lang \& Stulz, 1994; Villalonga, 2004). To study how diversification advantage changes with relatedness and complexity, we run our simulation at levels of $K$ ranging from 0 to 11 and $R$ ranging from 1 to $12 .{ }^{14}$ The reported results for each combination of $K$ and $R$ are the average of 100 randomly generated simulation runs where in each run the performance of 100 firms are aggregated (Levinthal, 1997). In common with most of the NK literature, we do not consider competition between firms in our simulation (though see Lenox, Rockart, \& Lewin, 2006, 2007 for noteworthy exceptions). Our measure of diversification advantage is thus best thought of as a measure of the advantage of diversified firms in terms of their internal efficiency or productivity, rather than their profitability per se.

\section{4 | ANALYSES AND FINDINGS}

\section{1 | Complexity, relatedness, and the long run effects of coordination}

We begin by modeling the long run effects of coordination by themselves: that is, we ignore short run synergies (setting $\delta=0$ ) and consider the pure effect of coordinating the choices of the $L$ elements of the two landscapes on the diversified firm's relative performance. In the absence of synergy,

is also a reason for assuming that $L \leq R$; for values of $L>R$ coordination costs would presumably exceed economies of scope, making coordination beyond that point sub-optimal.

${ }^{11}$ Making synergies a function of $\alpha$ also means that synergies increase with coordination at a decreasing rate. As online Appendix B shows, our main findings are robust to making synergies independent of $\alpha$, or making $\alpha$ independent of $R$.

${ }^{12}$ Intuitively, a value of $\delta=\frac{1}{N}$ means that the capability is $8.33 \%$ more productive on average in each business as a result of being shared, even after accounting for the coordination costs associated with sharing.

${ }^{13}$ For ease of presentation, the results presented below normalize performance by setting the value of the global peak on each landscape to 1 . Our findings are unchanged if we use non-normalized scores.

${ }^{14}$ In the interests of parsimony, the results below show only the simulations corresponding to $K=2,6$, and 10 , that is, low complexity, moderate complexity, and high complexity respectively. Results for other values of $K$ (available from the authors) are consistent with the pattern shown by these values. We also do not plot values of $R=0$ since, by definition, there is no difference between a diversified firm and its focused counterparts in that case. 


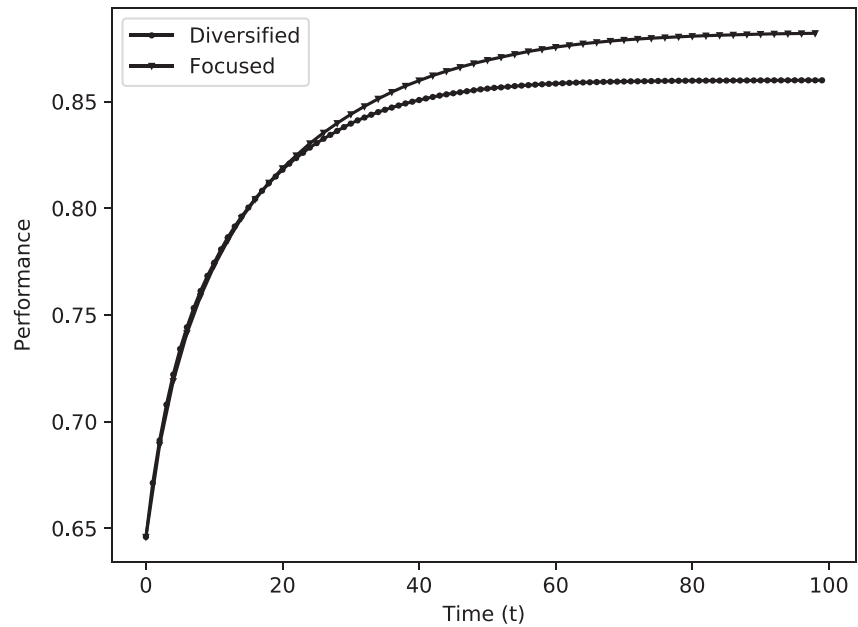

F I G URE 3 Diversified vs. focused firm performance over time (without synergy)

coordination between businesses has no immediate benefits, so it is unclear that a firm would ever choose to diversify. ${ }^{15}$ But that is precisely where we want to begin-by isolating the effect of relatedness and complexity on the adaptation of diversified firms - before expanding our analysis to include the effect of synergies.

Figure 3 shows the effect of coordinating activities between businesses in the diversified firm. Specifically, it shows how the average performance of a diversified firm evolves over time (starting from a random point on the landscape) compared to the combined average performance of two focused firms over the same period. For illustrative purposes, we choose moderate values of relatedness $(R=6)$ and complexity $(K=6)$ for this figure, though we could draw similar graphs for any feasible value of $R$ and $K$. Figure 3 shows that while the diversified firm starts off at the same performance level as its focused counterparts, its performance soon falls below that of the focused firms. Eventually, the performance of the focused firms as well as that of the diversified firm asymptotes, with the diversified firm's steady state performance being substantially below that of the focused firms, even though it started at the same level. This persistent gap in the performance of the diversified firm relative to its focused counterparts is the result of its inability to fully adapt within businesses as it coordinates between businesses.

Figure 4a plots long run diversification advantage (i.e., the value of diversification advantage once both diversified and focused firms have arrived at a steady state) as a function of the level of relatedness $(R)$ for low, moderate, and high levels of complexity $(K=2,6,10$, respectively), as well as for the baseline case where there is no interdependence within the businesses $(K=0)$. Figure $4 \mathrm{a}$ shows that, absent short run synergies, the long run performance of diversified firms is always lower than that of their focused counterparts; in other words, the rigidity effects of coordinating between businesses dominate the cross-business learning effects.

Figure 4a also shows that, given complexity, this negative long run effect of coordination has a curvilinear relationship with relatedness. The disadvantage of diversified firms increases with relatedness but at a decreasing rate, with the relationship eventually reversing for high relatedness with

\footnotetext{
${ }^{15}$ In fact, by setting $\delta=0$ we are assuming that net synergies are zero. Given that coordination between businesses will give rise to bureaucratic costs (Jones \& Hill, 1988; Williamson, 1985) even if they do not result in economies of scope, one might further consider the case where net synergies were negative, that is, $\delta<0$. We do not consider that case here, since we are only interested in the consequences of coordination for adaptation.
} 
FIGURE 4

(a) Long run effects of coordination between businesses.

(b) Cross-business learning benefits

(c) Rigidity effect
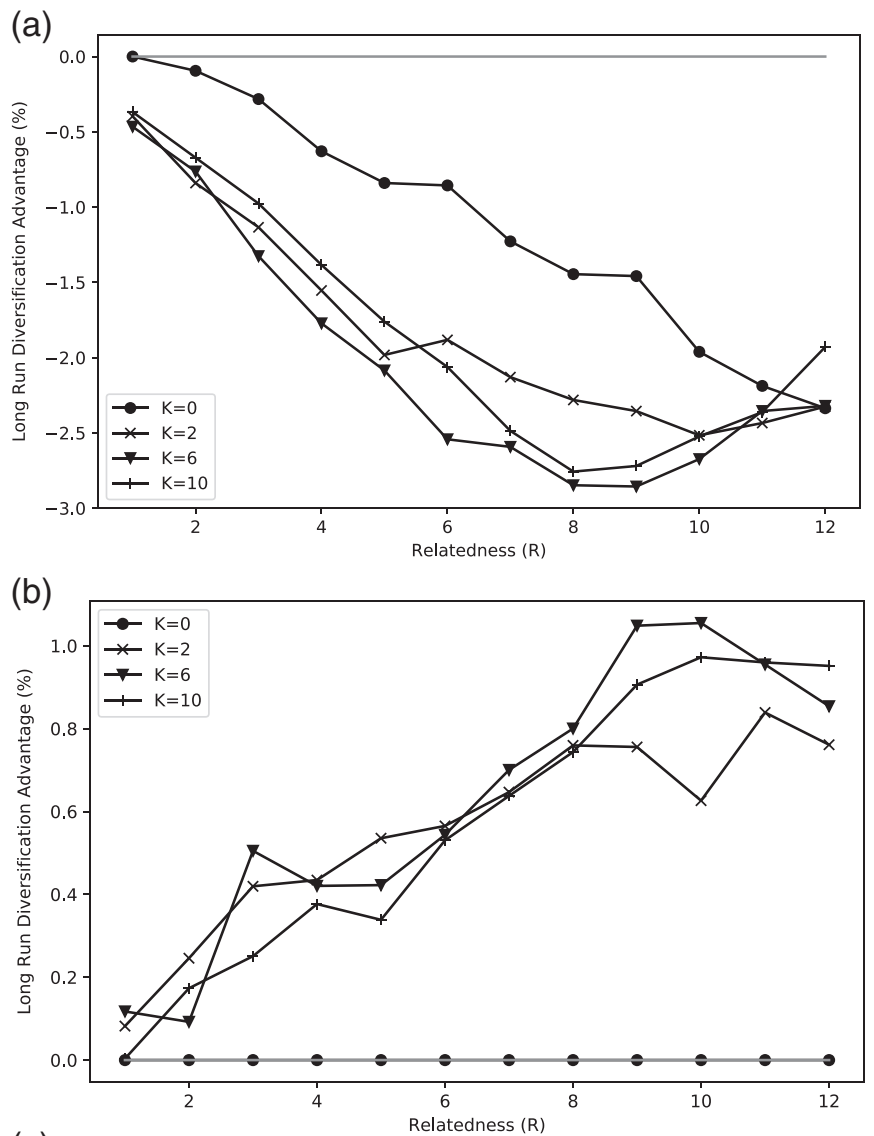

(c)

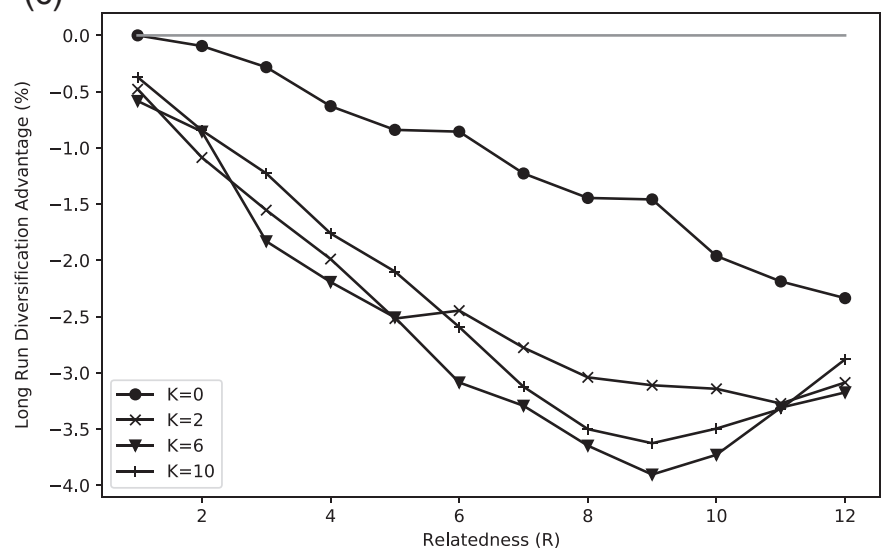

moderate to high complexity $(K=6,10){ }^{16}$ Thus, moderately related diversifiers suffer long run negative consequences of coordinating between businesses that are almost as severe as those for highly related diversifiers, and potentially more severe if complexity is moderate to high. Note that this nonlinear relationship between long run effects and relatedness only arises on account of complexity within businesses; where such complexity is absent (the $K=0$ case), diversification advantage more or less steadily decreases with relatedness. Moreover, the nonlinear effect of relatedness means that 
the effects of complexity essentially disappear at the highest levels of relatedness, with the $K=2$, $K=6$, and $K=10$ lines rising up to meet the $K=0$ line at $R=12$.

To see what drives this overall diversification disadvantage, we break it down into its two constituent parts (as discussed earlier and shown in Figure 1): rigidity effects and cross-business learning effects. In order to separate the two, we start by allowing the diversified firm to achieve a steady state, then relax the constraints placed on it (by setting $L=0$ ) and allow it to search further, eventually comparing the steady state performance of this first constrained then unconstrained firm to that of its never constrained (focused) counterparts. The intuition is that even if we stop coordinating between businesses, the benefits of past learning persist - each business continues to use the best practices and routines it has discovered as a consequence of coordinating with the other-even if there is no further learning. ${ }^{17}$ At the same time, stopping coordination unconstrains each business, allowing it to make autonomous choices, and thus overcome past rigidity. The relative advantage of the newly unconstrained firm thus provides a measure of the cross-business learning effects of coordination in the long run. Figure $4 \mathrm{~b}$ graphs these cross-business learning effects as a function of relatedness for the same four values of $K(0,2,6$, and 10) used in Figure $4 \mathrm{a}$.

Figure $4 \mathrm{~b}$ shows that the benefits of cross-business learning generally increase with relatedness. This is fairly intuitive: the greater the similarity between two businesses, the greater the advantage from sharing knowledge between them. It also shows that in the absence of complexity $(K=0)$, there are no long run cross-business learning benefits of coordination between businesses. The intuition here is that so long as each activity is independent of the other, both focused and diversified firms will eventually arrive at the optimal choice for that activity, so the diversified firm has no long run advantage relative to focused firms. ${ }^{18}$ The cross-business learning effects shown in Figure $4 \mathrm{~b}$ arise because in the presence of complexity single business firms tend to get stuck at lower value local optima, which diversified firms avoid because coordination between businesses allows them to discover combinations of choices they would not otherwise have made. ${ }^{19}$

Figure $4 \mathrm{c}$ then plots the rigidity effects of coordination, which are calculated by subtracting the cross-border learning effect in Figure $4 \mathrm{~b}$ from the net long run effect in Figure 4a. It shows that rigidity effects initially increase with relatedness, but the rate of increase decreases as the two businesses grow more related, with the relationship reversing for high values of complexity and relatedness. As in Figure 4b, this nonlinearity is a result of complexity; in the absence of complexity the relationship between relatedness and rigidity is basically linear. The intuition here is that as relatedness increases, the two businesses become more similar, so the constraint imposed by greater coordination becomes less costly - what is good for one business is less harmful for the other.

Figure 5 plots the same long run (dis)advantage of diversified firms as Figure $4 \mathrm{a}$, only this time as a function of complexity $(K)$ for low, moderate, and high levels of relatedness $(R=2,6,10$, respectively). It shows that the long run effect of coordination has a nonlinear relationship with complexity as well. We see a clear pattern of a rapid fall in diversification advantage as we introduce

\footnotetext{
${ }^{17}$ To be clear, we are not suggesting that diversified firms will, or should, stop coordinating activities once they achieve a steady state. The procedure described here is simply a mechanical exercise to help us isolate cross-business learning effects from rigidity effects; one that only works so long as we assume that once the coordinated firm reaches a steady state all potential learning benefits have already accrued.

${ }^{18}$ Cross-business learning may still help the diversified firm arrive at the optimal choice for each activity faster, even without complexity, but we are only focused on the long run consequences of coordination here.

${ }^{19}$ The extent of cross-business learning may also vary with the level of similarity between the structure of interdependence in the two businesses. While fully exploring that dimension is beyond our current scope, online Appendix D reports the results of a robustness check where we allow the structure (and extent) of interdependence to vary across the landscapes, and shows that our main findings are largely unaffected by this change.
} 
F I G URE 5 Long run effects of coordination as a function of complexity

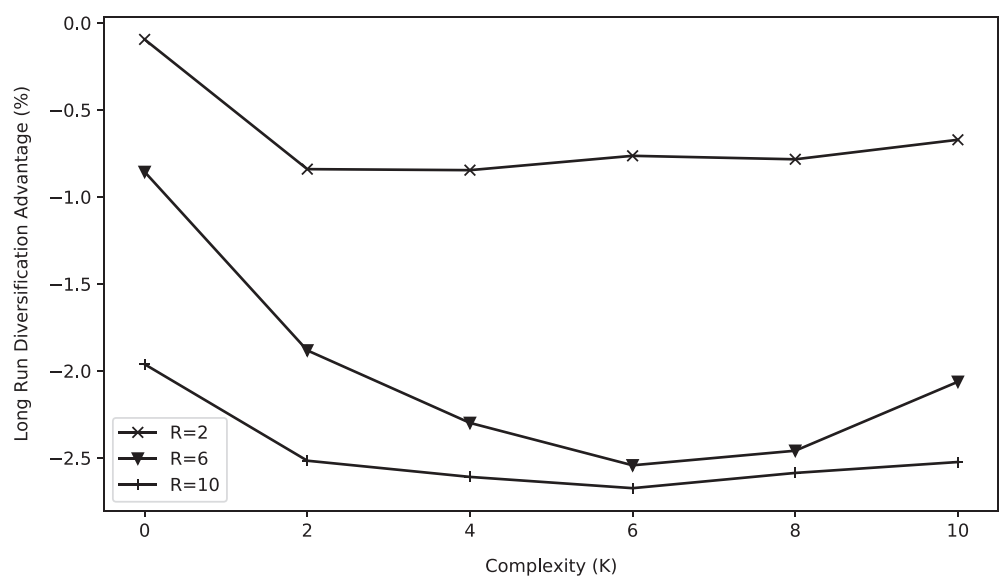

even modest levels of complexity $(K=2,4)$, followed by a relatively flat (and, in some cases, slightly increasing) slope as complexity increases further. This is consistent with what we had already seen in Figure 4a, where the line for $K=2$ lay far below the line for $K=0$ but the line for $K=10$ was quite close to the line for $K=2$. This nonlinear effect of complexity is important because it implies that negative consequences of coordination between businesses for adaptation do not only matter for extremely complex businesses, where all the different activities within a business are tightly tied to each other. Even in cases where every activity in the business is only linked to one or two other activities, such within-business complexity will rapidly amplify the constraints of any coordination between businesses, compromising the diversified firm's ability to successfully adapt. The basic intuition for this nonlinear effect is that every additional activity coordinated between businesses constrains several other choices in both businesses. So, for instance, with a complexity of $K=3$ even coordinating two activities between businesses $(L=2)$ means that the number of constrained choices may be as high as eight. This multiplier effect means that even at relatively modest levels of both $R$ and $K$, most of the firm's choices are already constrained, so further increases in complexity have little additional negative effect on adaptation in diversified firms.

\section{2 | The effects of synergy}

While our analyses thus far examine the long run consequences of coordination between businesses as a function of relatedness and complexity, it is clear that this is only part of what distinguishes diversified firms from their focused counterparts. To fully assess the performance consequences of coordination, we need to factor in not only these long run consequences, but also the short run synergies (net of bureaucratic costs) that the diversified firm enjoys as a result of coordinating activities between businesses.

Figure 6a shows the effect of considering synergies between businesses; specifically, it revisits the results in Figure 3, comparing the average performance of a diversified firm to that of its focused counterparts over time, only this time allowing for synergies between businesses (specifically, setting $\delta=\frac{1}{N}$ ). Figure $6 \mathrm{~b}$ then plots the performance advantage of the diversified firm (corresponding to Figure 6a) over time. As the figures show, the inclusion of synergies means that the diversified firm initially enjoys a performance advantage. This is because it is immediately able to enjoy the benefits of synergy resulting from the sharing of capabilities between its businesses. As time progresses, 
however, the very coordination between businesses that enabled it to realize those synergies also makes it harder for each business to adapt, so the diversifier's initial advantage relative to the focused firms deteriorates, eventually (in this case) turning negative in the long run. Thus, the diversified firm benefits from synergies between businesses in the short run but these benefits may be (partly or wholly) undone by the long run negative effects of coordination between businesses. Thus, given complexity, the promise of synergies may drive firms to coordinate activities between businesses in a way that leads to lower (and potentially negative) long run performance.

Figure $7 \mathrm{a}-\mathrm{c}$ explores this point further, showing how long term diversification advantage (as a function of $R$ and $K$ ) changes as we increase the level of synergy (to $\delta=\frac{1}{2 N}, \frac{1}{N}, \frac{3}{2 N}$, respectively). As these figures make clear, while the addition of synergy increases long run diversification advantage, especially for high values of relatedness (as we would expect), it does not fundamentally alter the

(a)

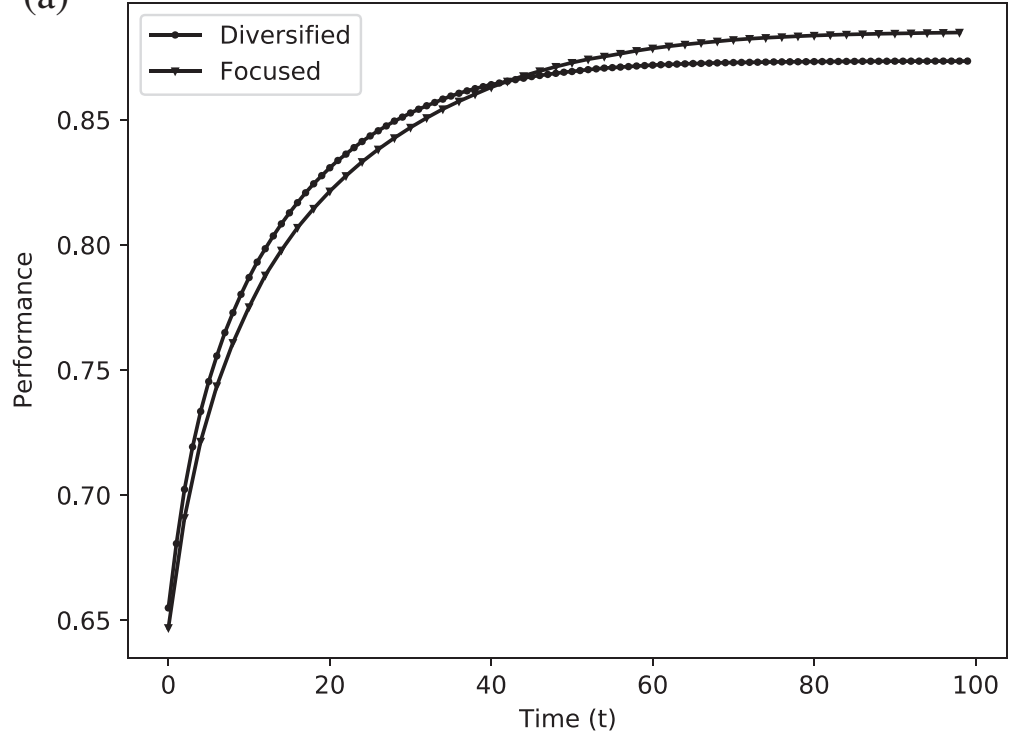

(b)

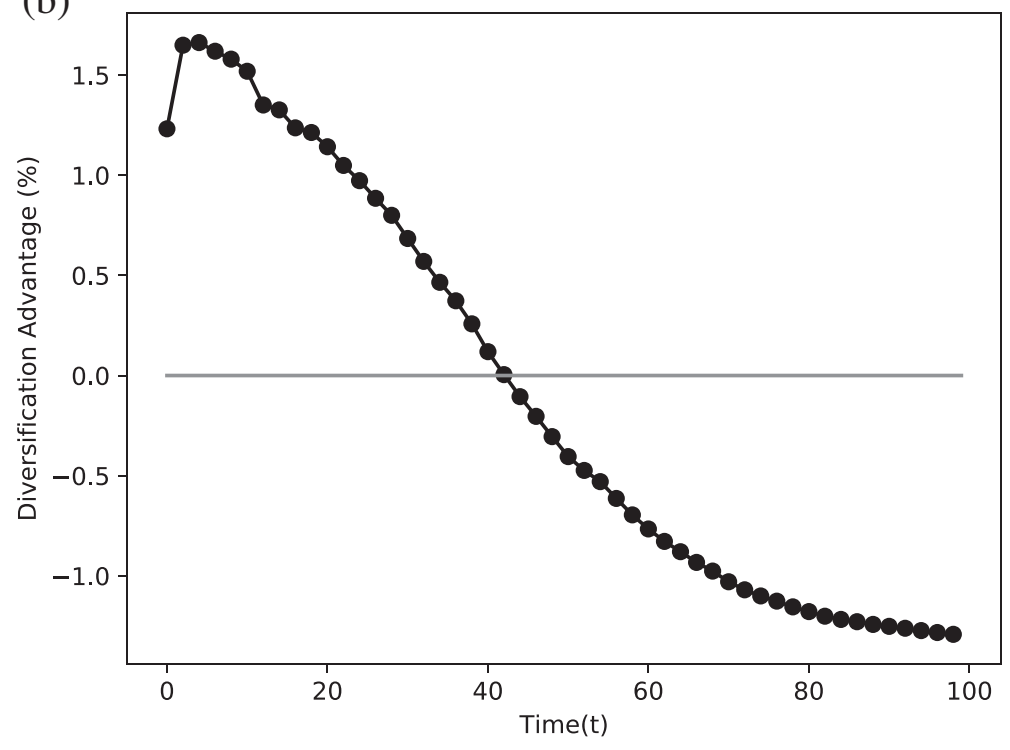

F I G URE 6 (a) Diversified vs. focused firm performance (with synergy). (b) Diversification advantage (with synergy) over time 
nonlinear relationship between relatedness and diversification advantage. We still see a nonlinear relationship between the long run advantage of the diversified firm and relatedness, with the diversified firm's advantage falling (and potentially turning negative) as relatedness initially increases, but then starting to rise as we approach high levels of relatedness. Thus, in the presence of complexity, moderate levels of relatedness continue to result in the weakest advantage for the diversified firm in the long run, precisely because the negative long run effects of coordination in this case dominate the modest synergies realized. Of course, with sufficiently high levels of synergy even a firm diversified into a moderately related business may realize a long run diversification advantage, but even in that case we would continue to see a nonlinear effect, with the increase in diversification advantage as we go from low to moderate relatedness being substantially lower than the corresponding increase when moving from moderate to high relatedness. Figure $7 d$ shows such a case, with synergies high enough that even at moderate levels of relatedness the diversified firm is not at a long run disadvantage. Note that this case requires setting $\delta=\frac{5}{2 N}$, implying that the firm's capabilities are over $20 \%$ more productive when shared between businesses, even after accounting for bureaucratic costs.

Figure $7 \mathrm{a}-\mathrm{d}$ also shows that as synergies rise, the long run performance advantage of highly related diversifiers rises steadily_ as we would expect—-so that not only do highly related diversifiers outperform their focused counterparts, but, other things being equal, the diversified firm's performance is highest with high relatedness, as it was not in Figure 4a. The intuition here is that as synergies increase, the benefits of being in highly related businesses come to dominate the negative effects of coordination on adaptation, even in the long run (especially in cases with high complexity). Finally, Figure 7a-d also continues to show a nonlinear effect of complexity on diversification advantage, with the gap between the $K=0$ line and the $K=2$ line being substantially greater than the gap between the $K=2$ and $K=10$ lines throughout.

\section{3 | Optimal coordination}

The results in Figure 7a-d assume that the diversified firm always chooses to coordinate all activities that are even slightly related across businesses, consistent with prior work that has generally associated higher relatedness with greater coordination (Jones \& Hill, 1988). That assumption makes sense so long as we consider only the short run effects of coordination, since in the short run the diversified firm is always better off coordinating any activities that result in net positive synergies, that is, setting $L=R$. Once we recognize that such coordination may have negative long run consequences, however, it becomes important to consider that the decision to coordinate activities between businesseseven those that are potentially related-is a choice (Zhou, 2011). So, for instance, a firm could choose to develop a different brand for each of its businesses, even if both businesses sold to the same segment of customers (Aggarwal \& Wu, 2015), and had a similar value proposition. In this section, we therefore consider what would happen if the firm were sufficiently foresighted to recognize that coordinating its choices across businesses would constrain it from adapting in the long run, and therefore chose the optimal level of coordination between businesses ex ante. ${ }^{20}$ Note that we continue to assume that firms may find it challenging to dynamically change their level of coordination given adjustment costs (Argyres et al., 2015, 2019), so that $L$, once chosen, does not change over time.

\footnotetext{
${ }^{20}$ Of course, being able to know the optimal level of coordination between businesses ex ante would require an almost heroic level of strategic foresight, especially when coupled with the fairly myopic version of local search assumed in our NK model. Nevertheless, examining the optimal coordination case is interesting because it allows us to consider how well the diversified firm could have done by endogenously choosing $L$.
} 

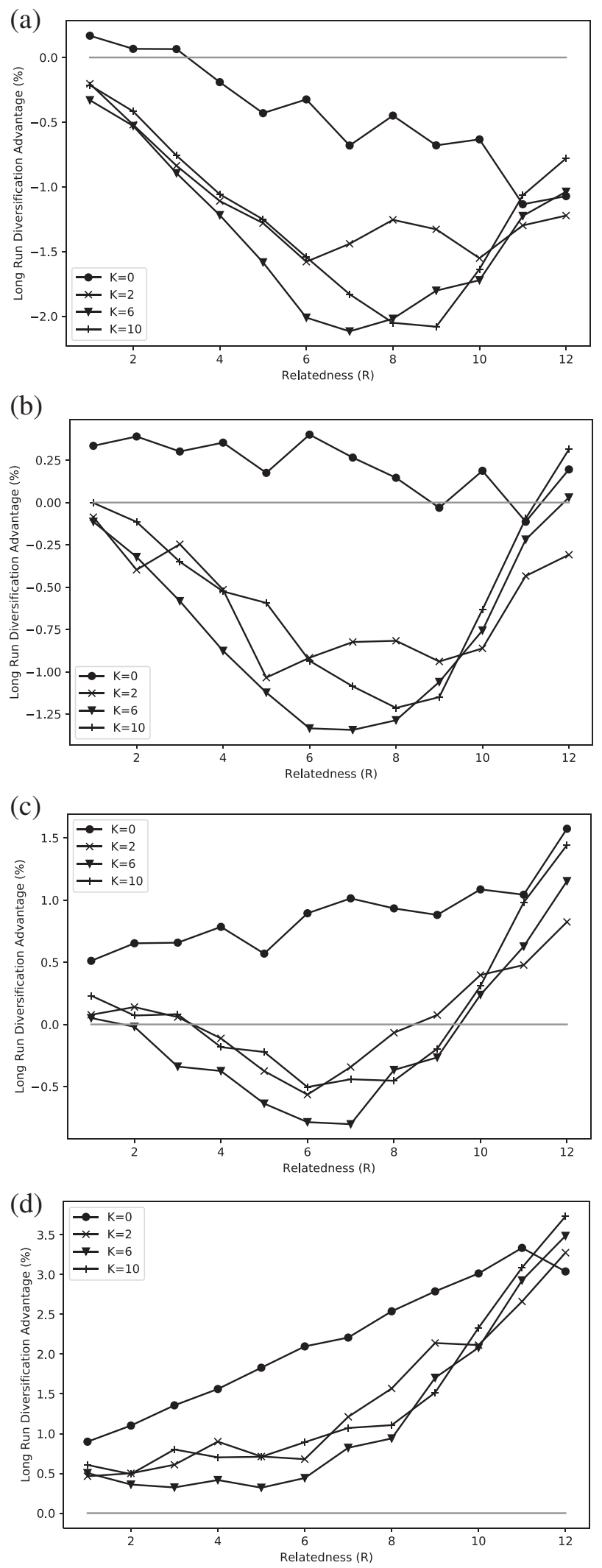

FIGURE 7 (a) Long run diversification advantage with low synergy $\left(\delta=\frac{1}{2 N}\right)$. (b) Long run diversification advantage with moderate synergy $\left(\delta=\frac{1}{N}\right)$. (c) Long run diversification advantage with high synergy $\left(\delta=\frac{3}{2 N}\right)$.

(d) Long run diversification advantage with extremely high synergy $\left(\delta=\frac{5}{2 N}\right)$ 


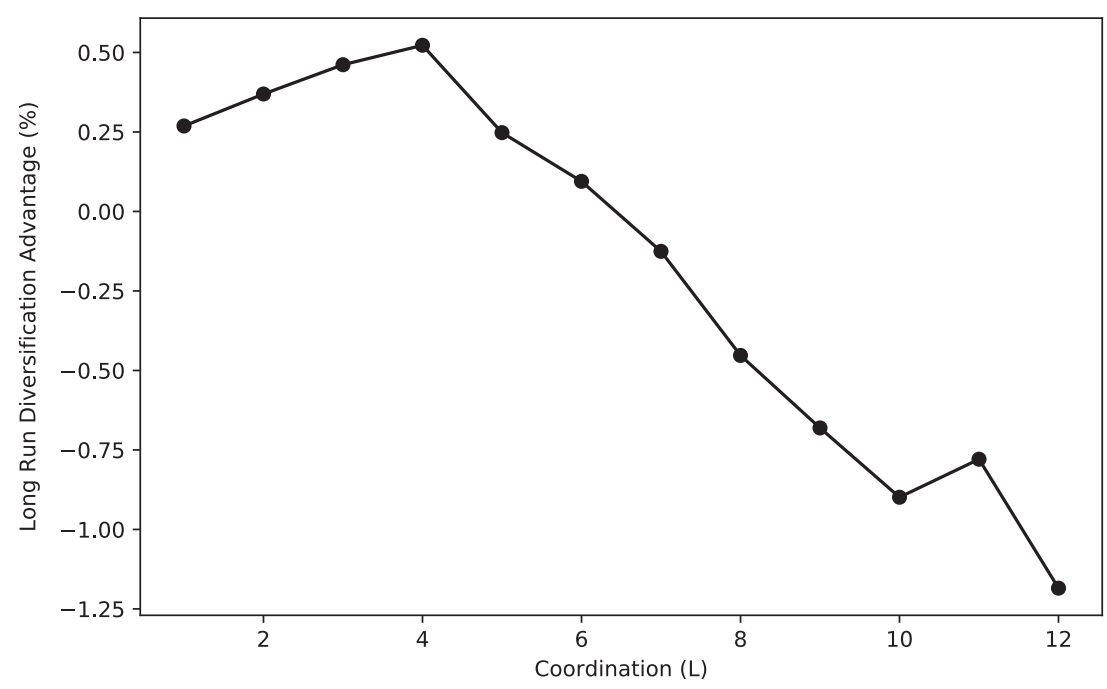

F I G U R E 8 Effect of changing coordination levels

In order to assess the optimal level of coordination, we simulate and derive the long run diversification advantage for all values of $L$ for given values of $R, K$, and $\delta$. Figure 8 shows the result of this analysis for one set of values: $R=8, K=10, \delta=\frac{3}{2 N}$. We then define $L^{*}$ as the value of $L$ where the firm's long run diversification advantage is highest: in the case shown in Figure 8 that would be $L^{*}=4$. Repeating this exercise for every value of $R, K$, and $\delta$ gives us the optimal coordination level that the diversified firm should choose, for any given set of parameter values. Clearly, $L^{*}=0$ if $\delta=0$; absent synergies, the diversified firm should never coordinate any activities between businesses, as evidenced by the uniformly negative performance of the diversified firm in Figure 4a earlier. Moreover, given that, by assumption, the firm can only realize synergies by coordinating between similar activities, $L^{*} \leq R$, that is, it never makes sense for the diversified firm to coordinate entirely dissimilar activities. ${ }^{21}$

Figure 9a-c shows the values of $L^{*}$ as a function of $R$ and $K$, for levels of synergy corresponding to those in Figure 7a-c, respectively. They show that, in general, $L^{*}<R$, that is, the diversified firm is better off coordinating only some of the similar activities between its businesses. In the extreme, they show that with low or even medium synergies $L^{*}=0$ with low to moderate relatedness, meaning that in such cases diversification may be a suboptimal choice, with the two businesses being better off if left to adapt autonomously (Williamson, 1991) despite the potential for short run synergies between them. ${ }^{22}$ Even when diversification is potentially valuable, moreover, the optimal number of activities to coordinate lies far below the number of potentially related activities between the two businesses, with this gap being highest for moderate levels of relatedness, and increasing at a decreasing rate with complexity. Only in the case of very high relatedness and complexity with high

\footnotetext{
${ }^{21}$ In addition, since by design activities are organized in decreasing order of similarity (and therefore synergy), in choosing $L^{*}$ the firm is not only choosing the optimal level of coordination, it is also choosing the activities that will yield the highest level of short run synergies given that level of coordination.

${ }^{22}$ In principle, such autonomy could be achieved by a single firm diversifying but not coordinating at all across businesses, though such an arrangement may be challenging, given the impossibility of selective intervention (Williamson, 1985); put differently, diversification only makes sense if there is at least some coordination between businesses (Hart \& Holmstrom, 2010).
} 


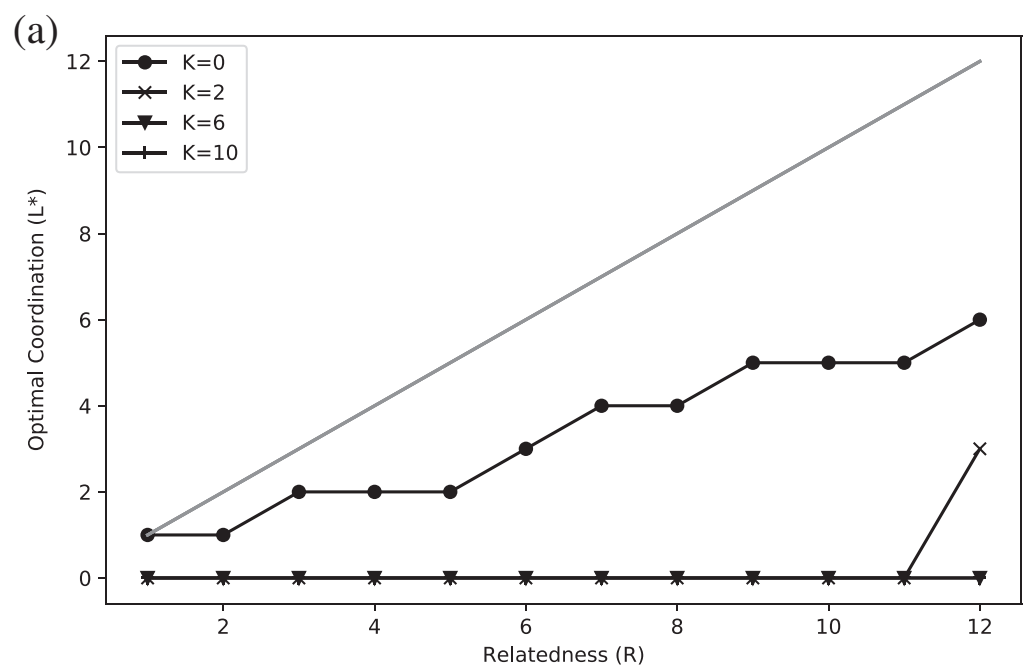

FIGURE 9

(a) Optimal coordination with low synergy.

(b) Optimal coordination with moderate synergy.

(c) Optimal coordination with high synergy

(b)

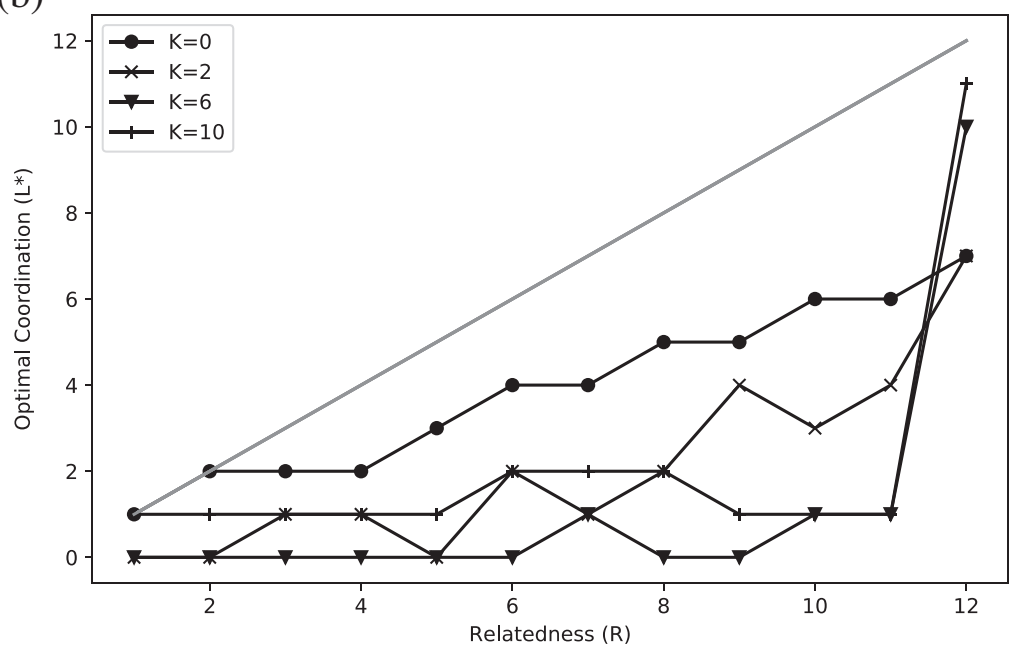

(c)

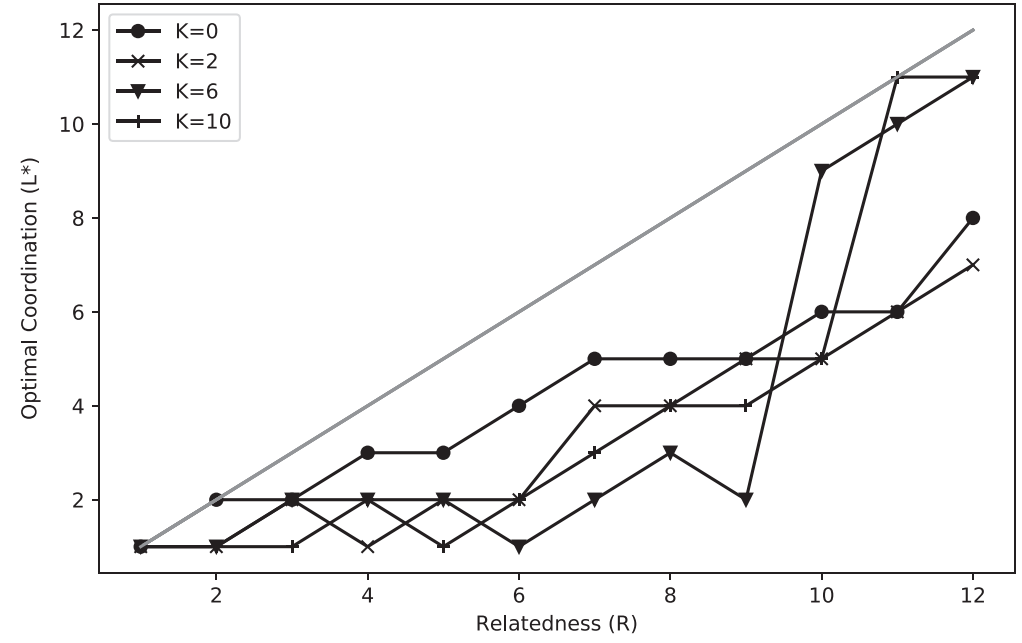


synergies is the benefit from synergies great enough (and the long run effects sufficiently small) to make it worthwhile for the diversified firm to coordinate all related activities between businesses.

The results in Figure 9a-c suggest that diversified firms may be susceptible to overcoordination between businesses. While conventional wisdom might suggest that the firm look for and realize every possible synergy between two businesses-and doing so might prove beneficial in the short run-the long run cost of doing so may be an inability to adapt in each business that will impose severe costs on the diversified firm, especially if complexity within businesses is high and relatedness between businesses is moderate. Instead, the diversified firm may be better off exploiting only a handful of the most promising synergies between the two businesses, while leaving several smaller synergies untapped, so as to retain the flexibility necessary to adapt within businesses.

This overcoordination problem is interesting because it highlights a relatively unexplored dimension of firm diversification. As previously mentioned, much of the prior research on coordination costs and their impact on diversification has focused on the breadth of a firm's diversificationasking how many businesses a firm should enter (Jones \& Hill, 1988) and how that answer changes depending on the relatedness of the businesses in question (Nayyar, 1992; Zhou, 2011). In contrast, our analysis emphasizes how much a diversified firm should coordinate between any two businesses, thus focusing attention on the depth of a firm's diversification. The findings in Figure $9 \mathrm{a}-\mathrm{c}$ thus suggest the existence of a problem of overcoordination that is distinct from, but parallel to, the problem of overdiversification frequently discussed in the literature (Markides, 1992, 1995) and offers an alternate but complementary reason why diversified firms may sometimes find themselves at a performance disadvantage relative to focused firms (Miller, 2004).

To further examine the performance of diversified firms, Figure 10a-c plots the long run performance advantage of the diversified firm, at the optimal level of coordination $\left(L^{*}\right)$ as shown in Figure $9 \mathrm{a}-\mathrm{c}$, respectively. In other words, they plot the maximum long run performance advantage ${ }^{23}$ the diversified firm could hope to achieve for the given values of relatedness $(R)$, complexity $(K)$, and synergy $(\delta)$, assuming it made the optimal ex ante choice on how much to coordinate between businesses. These figures show that, once the overcoordination problem is resolved, diversification advantage unilaterally increases with relatedness, but in a nonlinear way. Specifically, while diversification into highly related businesses almost always results in a performance advantage, diversification into moderately related businesses is not especially advantageous, being generally comparable to diversification into largely unrelated businesses. The intuition behind this result is that the long run negative effects of coordination between businesses in moderately related diversifiers mean that they are generally better off coordinating only a few of the many activities they could potentially coordinate $\left(L^{*}\right.$ is low), if they coordinate at all, so that they essentially act like unrelated diversifiers, and achieve similar performance levels.

The results in Figure 10a-c-coupled with those in Figure 9a-c-suggest that not all synergies are worth tapping, especially for businesses with high complexity. In many cases, firms in complex businesses may be better off not diversifying into unrelated or moderately related businesses at all; while doing so may offer some short run synergies, the long run negative impact of coordination on adaptation means that both businesses are better off staying autonomous. Even where diversification is valuable, these results, along with those in Figure $7 \mathrm{a}-\mathrm{c}$, offer a strong case in favor of conglomerate diversification, that is, diversification where the firm leaves its businesses largely independent, coordinating only a few activities between them. Not only are all but the most strongly related diversifiers better off in the long run choosing a conglomerate structure where they limit coordination to

\footnotetext{
${ }^{23}$ Note that the diversification advantage is always positive at $L^{*}$; if that were not the case, the firm would always have the option of not coordinating at all and achieving a performance identical to that of its focused peers.
} 
(a)

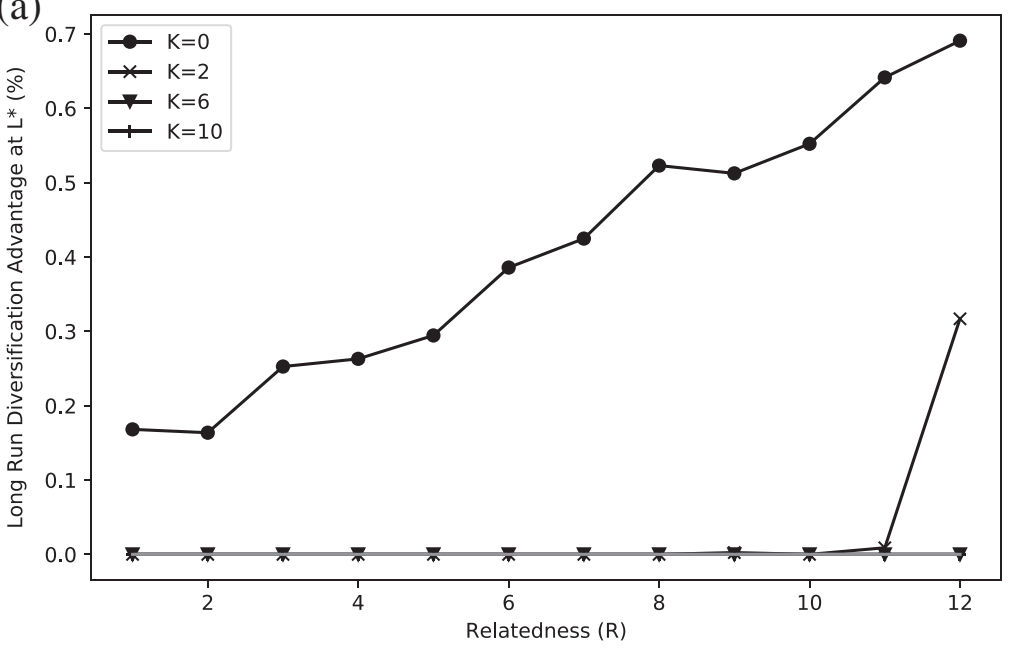

(b)

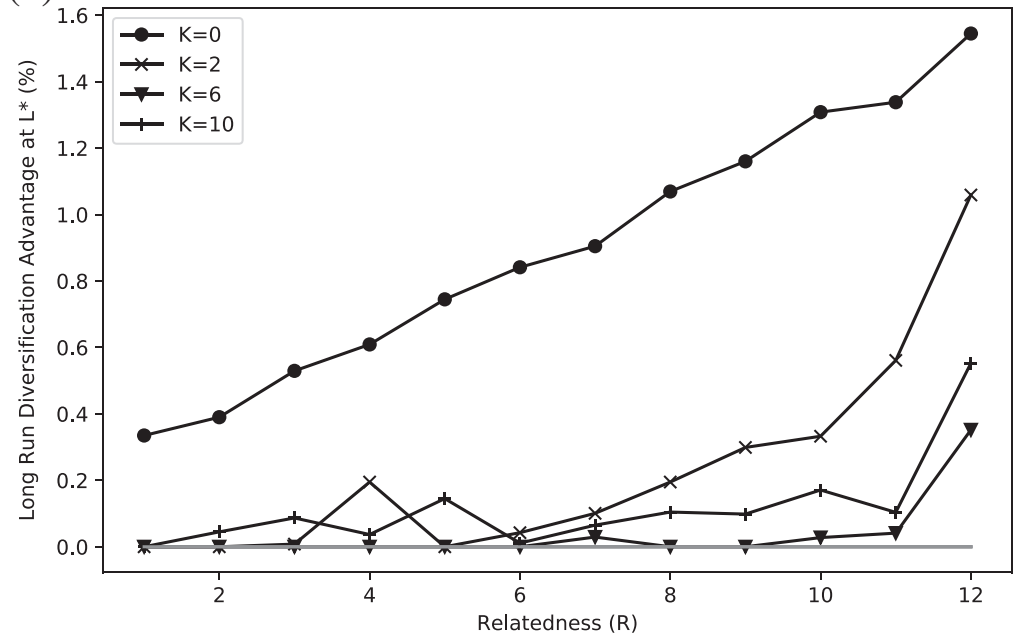

(c)

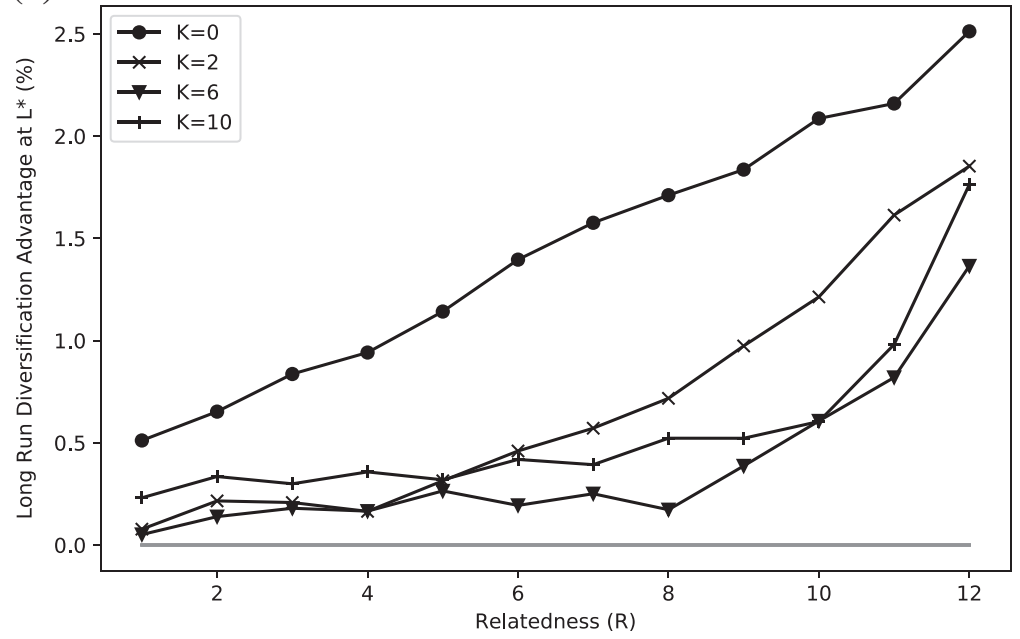

F I G U RE 10 (a) Optimal long run advantage with low synergy. (b) Optimal long run advantage with moderate synergy. (c) Optimal long run advantage with high synergy 
only a few key activities, but failing to make that coordination choice correctly may have far more negative long-term consequences for moderately related diversifiers than for largely unrelated diversifiers. Of course, firms are still better off diversifying into highly related businesses, but such businesses (where the majority of two businesses activities share similarities with each other) may not always be available.

\section{5 | CONCLUSION AND DISCUSSION}

Our study sheds new light on the consequences of coordination between businesses for the long run performance of diversified firms. Using a simulation based approach, we show that the coordination of activities between businesses in diversified firms limits adaptation within businesses. While coordination enables diversified firms to realize synergies (net of bureaucratic costs), giving them an advantage relative to single business firms in the short run, this advantage may decline in the long run as the individual businesses fail to keep up with their focused counterparts. Moreover, this effect is jointly moderated by complexity within and relatedness between businesses. In particular, this negative effect is highest for moderately related diversifiers with moderate to high complexity, so that firms diversifying into moderately related businesses in pursuit of short run synergies may find themselves at a disadvantage compared to their single business counterparts in the long run. Given complexity within its businesses, a firm may therefore be better off limiting the extent of coordination between businesses, foregoing marginal synergies in order to preserve long run flexibility. Moreover, these negative long run effects of coordination mean that, even with optimal levels of coordination between businesses, the long run performance advantage of diversified firms may increase at an increasing rate with relatedness, with moderately related diversifiers doing just marginally better than unrelated diversifiers and substantially worse than highly related diversifiers.

The results of our simulation thus extend research on diversification as a source of rigidity (Natividad \& Rawley, 2016; Rawley, 2010) — as well as the costs of coordination in diversified firms more generally (Jones \& Hill, 1988; Zhou, 2011)—by highlighting the role of complexity within businesses in limiting diversified firms' ability to adapt (Burgelman et al., 2019). On one hand, most of the findings from our analysis are driven by the presence of complexity; where there is no interdependence between activities within businesses $(K=0)$, we do not see any of the nonlinear effects our study highlights. On the other, we also show that our nonlinear effects arise with fairly modest levels of complexity $(K=2,4)$, such as we would expect to see in many firms, and are not limited to highly complex businesses. As such, our simulation results emphasize the importance of keeping within-business complexity in mind when considering the costs of coordination and the limits to firm scope. In doing so, our study serves as a potential bridge between work in corporate strategy that has studied the effects of interdependence between businesses (Rawley, 2010; Zhou, 2011) and work on search and adaptation that has highlighted the role of complexity in the context of a single business (Ethiraj \& Levinthal, 2004; Gavetti \& Levinthal, 2000; Levinthal, 1997).

By examining the adaptive consequences of coordination between businesses, our study also complements and extends recent work that has highlighted the role of organizational scope choices as a source of rigidity (Aggarwal \& Wu, 2015; Claussen et al., 2015; de Figueiredo et al., 2015; Gartenberg, 2014; Shaver, 2006; Sorenson, 2003). We contribute to this work by stressing the gap between a diversified firm's short run and long run performance, showing that, in the presence of complexity, the same choices that maximize synergies in the short run may also compromise long run performance by limiting the firm's ability to adapt. As such we offer an additional potential explanation for why diversified firms may sometimes operate at a discount to focused firms: one that 
does not require either self-interested behavior on the part of managers (Lang \& Stulz, 1994) or adverse selection of underperforming firms into diversification (Miller, 2004; Villalonga, 2004). The results from our model are thus also consistent with prior empirical work showing that diversification is associated with less innovation (Hoskisson \& Hitt, 1988; Hoskisson \& Johnson, 1992) and that diversification is more advantageous when diversified firms sustain their innovative efforts (Miller, 2006). Our study also shows that these negative effects of coordination do not monotonically increase with interdependence between businesses, as prior work might suggest (Natividad \& Rawley, 2016; Rawley, 2010; Zhou, 2011). In particular, we show that-consistent with potential for within-firm replication stressed in evolutionary theory (Nelson \& Winter, 1982; Rivkin, 2001; Zollo \& Winter, 2002) - an important source of value in diversified firms is the ability to transfer knowledge of successful adaptations in one business to the other (Kim \& Anand, 2018; Miller et al., 2007; Williams, 2007), and that these cross-business learning benefits may at least partially offset the rigidity effects of coordination between businesses.

Our study also contributes to the study of corporate diversification more generally. While the focus of this work has often been on the breadth of a firm's diversification-examining how many businesses firms enter and the consequences of doing so (Jones \& Hill, 1988; Palich et al., 2000; Zhou, 2011) — we draw attention to the depth of a firm's diversification, that is, how much it coordinates between any two businesses. While prior work has thus highlighted the problem of excessive diversification (Markides, 1992, 1995), arguing that diversified firms underperform their focused counterparts because they compete in too many businesses or choose the wrong businesses, we suggest that diversified firms may also be susceptible to a problem of overcoordination. Our findings suggest that choosing a level of internal coordination such that the marginal bureaucratic costs just offset the marginal economies of scope in the short run (Jones \& Hill, 1988) may prove suboptimal in the long run, and that diversified firms may therefore benefit from limiting the extent of coordination between their businesses, foregoing some short run synergies in order to retain long run flexibility. ${ }^{24}$ By emphasizing that the extent of coordination between businesses is a choice (Zhou, 2011), our study also suggests that firms may trade-off breadth and depth, strategically choosing to realize fewer synergies between businesses as they widen their portfolio.

As such, our study offers a novel rationale for conglomerate diversification, suggesting that firms may choose to diversify across relatively unrelated businesses (or, equivalently, treat the moderately related businesses they enter as though they were largely unrelated, coordinating only one or two key activities between them) because doing so allows them to be more flexible within businesses. It thus formalizes and extends early work which showed that the M-form structure is most valuable for unrelated diversifiers (Hoskisson, 1987; Hoskisson, Harrison, \& Dubofsky, 1991) suggesting that the virtue of such a structure may lie in enabling the kind of limited coordination that is optimal in the long run. Our study also speaks to the question of whether firms should diversify at all, suggesting that even where there is some short term potential to benefit from economies of scope between moderately related businesses, despite the costs of information transfer and sharing involved (Jones \& Hill, 1988; Zhou, 2011), firms in complex businesses may be better off in the long run by not diversifying. ${ }^{25}$ Our findings thus re-emphasize the fundamental tension between coordination and adaptation within organizational hierarchies (Williamson, 1991), and extend recent work on the effect of

\footnotetext{
${ }^{24}$ Our study also relates to work on post-merger integration and the advantages of leaving acquired targets independent (Puranam, Singh, \& Chaudhuri, 2009; Puranam, Singh, \& Zollo, 2006; Puranam \& Srikanth, 2007).

${ }^{25}$ While we consistently treat the complexity of the firm's business as exogenous-consistent with both the NK modeling literature (Levinthal, 1997) and empirical work examining the effect of interdependence within businesses on performance (Lee \& Alnahedh, 2016; Lenox et al., 2010)—a parallel implication of our findings is that firms seeking to tap into synergies between moderately related businesses may be better off choosing lower levels of complexity.
} 
within business complexity on organizational scope and structure choices (Brahm \& Tarzijan, 2016; Weigelt \& Miller, 2013).

In emphasizing the idea of optimal coordination, our study also speaks to work on dynamic capabilities (Helfat et al., 2007; Helfat \& Winter, 2011; Teece, 2007). As our simulation results show, choosing the right level of coordination between businesses has substantial performance implications, and the capability to coordinate optimally between businesses may thus be an important dynamic capability for diversified firms. While our model does not consider the potential for firms to dynamically adjust their level of coordination, an implication of the trade-off between short run synergies and long run flexibility we highlight is that an important capability for diversified firms is the ability to constantly adjust their internal structure to orchestrate their capability choices across businesses (Helfat \& Peteraf, 2003; Helfat \& Raubitschek, 2000, 2018) and to realize untapped synergies while limiting disruptions and remaining flexible (Karim, 2006; Karim \& Kaul, 2015). In fact, our findings for the cross-business learning effect suggest that, in the presence of complexity, businesses may not only learn best practices on specific activities from each other, they may also learn how best to organize the various activities within a businesses in order to best manage the interdependencies between them.

Though not the primary focus of our study, our findings also have implications for the growing literature on inter-temporal economies of scope (Helfat \& Eisenhardt, 2004; Levinthal \& Wu, 2010) and the potential for diversified firms to redeploy their resources across businesses over time (Folta, Helfat, \& Karim, 2016; Kaul, 2012; Sakhartov \& Folta, 2014, 2015; Vidal \& Mitchell, 2015; Wu, 2013). While this work emphasizes the benefits that firms can realize by redeploying resources from one business to the other (Folta et al., 2016; Helfat \& Eisenhardt, 2004; Levinthal, 2017; Lieberman, Lee, \& Folta, 2017), relatively less attention has been paid to the costs of maintaining this option to redeploy (Levinthal, 2017; Sakhartov \& Folta, 2015). To the extent that maintaining the redeployability of a resource (Anand, Kim, \& Lu, 2016; Folta et al., 2016) means ensuring that it remains compatible with its potential use in a future business, it may constrain the firm's ability to adapt that resource to its current use; consistent with this, empirical work has shown that diversifying firms have less specialized capabilities ex ante (Miller, 2004). Thus, the need to maintain resource compatibility between current and future businesses may produce negative effects similar to those of coordinating resources choices between current businesses. Future work could extend our simulation model by considering redeployment into a new market, comparing the performance of redeployers to that of diversifying or de novo firms (Agarwal, Echambadi, Franco, \& Sarkar, 2004; Ganco \& Agarwal, 2009; Kapoor \& Furr, 2015; Moeen \& Agarwal, 2017; Qian et al., 2012).

Future work could also build on our simulation model in other ways. By extending the familiar NK model to a diversified firm setting, our study provides the foundation for a range of additional analyses of how such firms adapt. Thus, future work could build on our model to examine questions of organizational structure and design (Kim \& Anand, 2018; Rivkin \& Siggelkow, 2003; Siggelkow \& Rivkin, 2005, 2006; Weigelt \& Miller, 2013), examining, for instance, how decision rights over the various related and unrelated activities are best assigned, or how different levels of centralization or decentralization (Alonso et al., 2008, 2015) and incentives for competition or cooperation (Hill et al., 1992) impact the speed of adaptation in diversified firms. Or it could study how the effects of coordination on adaptation we document change if we allow the two businesses to vary in either the level of their complexity (i.e., assume a different $K$ for each landscape) or its structure (Rivkin \& Siggelkow, 2007).

Finally, future work could also study the implications of our findings empirically. While the mapping between a simulation model and the real world is necessarily imperfect, our study does offer 
several testable propositions. It suggests, for instance, that the performance advantage of diversified firms may attenuate with age-with both the profitability and the odds of survival of diversified firms relative to their focused counterparts declining over time-and that this attenuation may be more pronounced for moderately related diversifiers than for highly related or unrelated diversifiers. It also suggests that firms that adopt a more conglomerate like structure may outperform others when diversifying into unrelated or moderately related businesses, and, more specifically, that such conglomerate structures should be especially valuable for innovation in each business. Future researchers could test these predictions empirically.

To conclude, we use a simulation based approach to study adaptation in diversified firms, arguing that coordination between businesses to realize synergies may limit adaptation within businesses. We find that these negative long run effects of coordination increase with both complexity within businesses and relatedness between businesses, but in a nonlinear way, being highest in the presence of moderate relatedness and complexity. The presence of these negative long run effects of coordination not only means that the long run performance advantage of diversified firms has a curvilinear relationship with relatedness, it also means that firms may be better off limiting the level of coordination between businesses so as to maintain long run flexibility. Our study thus points to a potential overcoordination problem in diversified firms, while also offering a novel rationale for conglomerate diversification.

\section{ACKNOWLEDGEMENTS}

We gratefully acknowledge insight and feedback from Editor Connie Helfat and two anonymous reviewers in helping us improve our study. We are also grateful to Gautam Ahuja, Nick Argyres, Felipe Csaszar, J.P. Eggers, Samina Karim, Daniel Levinthal, Hart Posen, and Maggie Zhou, as well as to participants at the Academy of Management Annual Meeting, Dartmouth Junior Faculty Strategy Research Summer Camp, INFORMS Conference, Strategic Management Society Annual Conference, and the Workshop on Scale and Scope at Cass Business School, for their comments and suggestions on previous versions of this manuscript. Authors contributed equally and are listed in alphabetical order.

\section{REFERENCES}

Agarwal, R., Echambadi, R., Franco, A. M., \& Sarkar, M. B. (2004). Knowledge transfer through inheritance: Spinout generation, development, and survival. Academy of Management Journal, 47(4), 501-522.

Aggarwal, V. A., \& Wu, B. (2015). Organizational constraints to adaptation: Intrafirm asymmetry in the locus of coordination. Organization Science, 26(1), 218-238.

Alonso, R., Dessein, W., \& Matouschek, N. (2008). When does coordination require centralization? American Economic Review, 98(1), 145-179.

Alonso, R., Dessein, W., \& Matouschek, N. (2015). Organizing to adapt and compete. American Economic Journal: Microeconomics, 7(2), 158-187.

Amihud, Y., \& Lev, B. (1981). Risk reduction as a managerial motive for conglomerate mergers. Bell Journal of Economics, 12(2), 605-617.

Amihud, Y., \& Lev, B. (1999). Does corporate ownership structure affect its strategy towards diversification? Strategic Management Journal, 20(11), 1063-1069.

Anand, J., Kim, H., \& Lu, S. (2016). Resource strategies: Toward a theoretical synthesis. In T. B. Folta, C. E. Helfat, \& S. Karim (Eds.), Advances in strategic management (Vol. 35, pp. 155-184). Bingley, England: Emerald Group Publishing Limited. 
Argyres, N. (1995). Technology strategy, governance structure and interdivisional coordination. Journal of Economic Behavior \& Organization, 28(3), 337-358.

Argyres, N., Bigelow, L., \& Nickerson, J. (2015). Dominant designs, innovation shocks, and the follower's dilemma. Strategic Management Journal, 36(2), 216-234.

Argyres, N., Mahoney, J., \& Nickerson, J. (2019). Strategic responses to shocks: Comparative adjustment costs, transaction costs, and opportunity costs. Strategic Management Journal, 40(3), 357-376. https://doi.org/10.1002/smj. 2984

Argyres, N., \& Zenger, T. (2012). Capabilities, transaction costs, and firm boundaries. Organization Science, 23(6), 1643-1657.

Brahm, F., \& Tarzijan, J. (2016). Toward an integrated theory of the firm: The interplay between internal organization and vertical integration. Strategic Management Journal, 37(12), 2481-2502.

Burgelman, R. A., Snihur, Y., \& Thomas, L. D. W. (2019). Adaptive portfolio rightsizing in the multi-business firm: An evolutionary framework. Academy of Management Proceedings, 2019(1).

Chatterjee, S., \& Wernerfelt, B. (1991). The link between resources and type of diversification: Theory and evidence. Strategic Management Journal, 12(1), 33-48.

Claussen, J., Kretschmer, T., \& Stieglitz, N. (2015). Vertical scope, turbulence, and the benefits of commitment and flexibility. Management Science, 61(4), 915-929.

Coase, R. H. (1937). The nature of the firm. Economica, 4(16), 386-405.

Csaszar, F. A., \& Siggelkow, N. (2010). How much to copy? Determinants of effective imitation breadth. Organization Science, 21(3), 661-676.

de Figueiredo, R. J. P., Rawley, E., \& Rider, C. I. (2015). Why are firms rigid? A general framework and empirical tests. Organization Science, 26(5), 1502-1519.

Denis, D. J., Denis, D. K., \& Sarin, A. (1997). Agency problems, equity ownership, and corporate diversification. Journal of Finance, 52(1), 135-160.

Denis, D. J., Denis, D. K., \& Sarin, A. (1999). Agency theory and the influence of equity ownership structure on corporate diversification strategies. Strategic Management Journal, 20(11), 1071-1076.

Ethiraj, S. K., \& Levinthal, D. (2004). Modularity and innovation in complex systems. Management Science, 50(2), $159-173$.

Feldman, E. R. (2014). Legacy divestitures: Motives and implications. Organization Science, 25(3), 815-832.

Folta, T. B., Helfat, C. E., \& Karim, S. (2016). Examining resource redeployment in multi-business firms. In T. B. Folta, C. E. Helfat, \& S. Karim (Eds.), Advances in strategic management (Vol. 35, pp. 1-17). Bingley, England: Emerald Group Publishing Limited.

Ganco, M., \& Agarwal, R. (2009). Performance differentials between diversifying entrants and entrepreneurial startups: A complexity approach. Academy of Management Review, 34(2), 228-252.

Gartenberg, C. (2014). Do parents matter? Effects of lender affiliation through the mortgage boom and bust. Management Science, 60(11), 2776-2793.

Gavetti, G., \& Levinthal, D. (2000). Looking forward and looking backward: Cognitive and experiential search. Administrative Science Quarterly, 45(1), 113-137.

Ghemawat, P. (1991). Market incumbency and technological inertia. Marketing Science, 10(2), 161-171.

Gulati, R., \& Singh, H. (1998). The architecture of cooperation: Managing coordination costs and appropriation concerns in strategic alliances. Administrative Science Quarterly, 43(4), 781-814.

Hart, O., \& Holmstrom, B. (2010). A theory of firm scope. Quarterly Journal of Economics, 125(2), 483-513.

Helfat, C. E., \& Eisenhardt, K. M. (2004). Inter-temporal economies of scope, organizational modularity, and the dynamics of diversification. Strategic Management Journal, 25(13), 1217-1232.

Helfat, C. E., Finkelstein, S., Mitchell, W., Peteraf, M., Singh, H., Teece, D., \& Winter, S. G. (2007). Dynamic capabilities: Understanding strategic change in organizations. Malden, MA: Blackwell Publishing.

Helfat, C. E., \& Peteraf, M. A. (2003). The dynamic resource-based view: Capability lifecycles. Strategic Management Journal, 24(10), 997-1010.

Helfat, C. E., \& Raubitschek, R. S. (2000). Product sequencing: Co-evolution of knowledge, capabilities and products. Strategic Management Journal, 21(10/11), 961-979.

Helfat, C. E., \& Raubitschek, R. S. (2018). Dynamic and integrative capabilities for profiting from innovation in digital platform-based ecosystems. Research Policy, 47(8), 1391-1399. 
Helfat, C. E., \& Winter, S. G. (2011). Untangling dynamic and operational capabilities: Strategy for the (n)everchanging world. Strategic Management Journal, 32(11), 1243-1250.

Hill, C. W. L., Hitt, M. A., \& Hoskisson, R. E. (1992). Cooperative versus competitive structures in related and unrelated diversified firms. Organization Science, 3(4), 501-521.

Hill, C. W. L., \& Hoskisson, R. E. (1987). Strategy and structure in the multiproduct firm. Academy of Management Review, 12(2), 331-341.

Holbrook, D., Cohen, W. M., Hounshell, D. A., \& Klepper, S. (2000). The nature, sources, and consequences of firm differences in the early history of the semiconductor industry. Strategic Management Journal, 21(10/11), 1017-1041.

Hoskisson, R. E. (1987). Multidivisional structure and performance: The contingency of diversification strategy. Academy of Management Journal, 30(4), 625-644.

Hoskisson, R. E., Harrison, J. S., \& Dubofsky, D. A. (1991). Capital market evaluation of M-form implementation and diversification strategy. Strategic Management Journal, 12(4), 271-279.

Hoskisson, R. E., \& Hitt, M. A. (1988). Strategic control systems and relative R\&D investment in large multiproduct firms. Strategic Management Journal, 9(6), 605-621.

Hoskisson, R. E., Hitt, M. A., \& Hill, C. W. L. (1991). Managerial risk taking in diversified firms: An evolutionary perspective. Organization Science, 2(3), 296-314.

Hoskisson, R. E., Hitt, M. A., \& Hill, C. W. L. (1993). Managerial incentives and investment in R\&D in large multiproduct firms. Organization Science, 4(2), 325-341.

Hoskisson, R. E., \& Johnson, R. A. (1992). Corporate restructuring and strategic change: The effect on diversification strategy and R\&D intensity. Strategic Management Journal, 13(8), 625-634.

Jensen, M. C., \& Meckling, W. H. (1976). Theory of the firm: Managerial behavior, agency costs and ownership structure. Journal of Financial Economics, 3(4), 305-360.

Jones, G. R., \& Hill, C. W. L. (1988). Transaction cost analysis of strategy-structure choice. Strategic Management Journal, 9(2), 159-172.

Kaplan, S., \& Henderson, R. (2005). Inertia and incentives: Bridging organizational economics and organizational theory. Organization Science, 16(5), 509-521.

Kapoor, R., \& Furr, N. R. (2015). Complementarities and competition: Unpacking the drivers of entrants' technology choices in the solar photovoltaic industry. Strategic Management Journal, 36(3), 416-436.

Karim, S. (2006). Modularity in organizational structure: The reconfiguration of internally developed and acquired business units. Strategic Management Journal, 27(9), 799-823.

Karim, S., \& Kaul, A. (2015). Structural recombination and innovation: Unlocking intraorganizational knowledge synergy through structural change. Organization Science, 26(2), 439-455.

Kaul, A. (2012). Technology and corporate scope: Firm and rival innovation as antecedents of corporate transactions. Strategic Management Journal, 33(4), 347-367.

Kaul, A. (2013). Entrepreneurial action, unique assets, and appropriation risk: Firms as a means of appropriating profit from capability creation. Organization Science, 24(6), 1765-1781.

Kim, S., \& Anand, J. (2018). Knowledge complexity and the performance of inter-unit knowledge replication structures. Strategic Management Journal, 39(7), 1959-1989.

Lang, L. H. P., \& Stulz, R. M. (1994). Tobin's q, corporate diversification, and firm performance. Journal of Political Economy, 102(6), 1248-1280.

Larkin, I., Pierce, L., \& Gino, F. (2012). The psychological costs of pay-for-performance: Implications for the strategic compensation of employees. Strategic Management Journal, 33(10), 1194-1214.

Lee, G. K. (2008). Relevance of organizational capabilities and its dynamics: What to learn from entrants' product portfolios about the determinants of entry timing. Strategic Management Journal, 29(12), 1257-1280.

Lee, G. K., \& Alnahedh, M. A. (2016). Industries' potential for interdependency and profitability: A panel of 135 industries, 1988-1996. Strategy Science, 1(4), 285-308.

Lenox, M. J., Rockart, S. F., \& Lewin, A. Y. (2006). Interdependency, competition, and the distribution of firm and industry profits. Management Science, 52(5), 757-772.

Lenox, M. J., Rockart, S. F., \& Lewin, A. Y. (2007). Interdependency, competition, and industry dynamics. Management Science, 53(4), 599-615. 
Lenox, M. J., Rockart, S. F., \& Lewin, A. Y. (2010). Does interdependency affect firm and industry profitability? An empirical test. Strategic Management Journal, 31(2), 121-139.

Leonard-Barton, D. (1992). Core capabilities and core rigidities: A paradox in managing new product development. Strategic Management Journal, 13(S1), 111-125.

Levinthal, D. A. (1997). Adaptation on rugged landscapes. Management Science, 43(7), 934-950.

Levinthal, D. A. (2017). Resource allocation and firm boundaries. Journal of Management, 43(8), 2580-2587.

Levinthal, D. A., \& March, J. G. (1993). The myopia of learning. Strategic Management Journal, 14(S2), 95-112.

Levinthal, D. A., \& Wu, B. (2010). Opportunity costs and non-scale free capabilities: Profit maximization, corporate scope, and profit margins. Strategic Management Journal, 31(7), 780-801.

Lieberman, M. B., Lee, G. K., \& Folta, T. B. (2017). Entry, exit, and the potential for resource redeployment. Strategic Management Journal, 38(3), 526-544.

Markides, C. C. (1992). Consequences of corporate refocusing: Ex ante evidence. Academy of Management Journal, 35(2), 398-412.

Markides, C. C. (1995). Diversification, restructuring and economic performance. Strategic Management Journal, 16 (2), 101-118.

Markides, C. C., \& Williamson, P. J. (1994). Related diversification, core competencies and corporate performance. Strategic Management Journal, 15(S2), 149-165.

Milgrom, P., \& Roberts, J. (1988). An economic approach to influence activities in organizations. American Journal of Sociology, 94, S154-S179.

Milgrom, P., \& Roberts, J. (1995). Complementarities and fit: Strategy, structure, and organizational change in manufacturing. Journal of Accounting and Economics, 19(2), 179-208.

Miller, D. J. (2004). Firms' technological resources and the performance effects of diversification: A longitudinal study. Strategic Management Journal, 25(11), 1097-1119.

Miller, D. J. (2006). Technological diversity, related diversification, and firm performance. Strategic Management Journal, 27(7), 601-619.

Miller, D. J., Fern, M. J., \& Cardinal, L. B. (2007). The use of knowledge for technological innovation within diversified firms. Academy of Management Journal, 50(2), 308-326.

Moeen, M., \& Agarwal, R. (2017). Incubation of an industry: Heterogeneous knowledge bases and modes of value capture. Strategic Management Journal, 38(3), 566-587.

Montgomery, C. A., \& Wernerfelt, B. (1988). Diversification, Ricardian rents, and Tobin's q. RAND Journal of Economics, 19(4), 623-632.

Natividad, G., \& Rawley, E. (2016). Interdependence and performance: A natural experiment in firm scope. Strategy Science, $1(1), 12-31$.

Nayyar, P. R. (1992). On the measurement of corporate diversification strategy: Evidence from large U.S. service firms. Strategic Management Journal, 13(3), 219-235.

Nelson, R. R., \& Winter, S. G. (1982). An evolutionary theory of economic change. Cambridge, MA: Belknap Press.

Nickerson, J., \& Zenger, T. (2008). Envy, comparison costs, and the economic theory of the firm. Strategic Management Journal, 29(13), 1429-1449.

Obloj, T., \& Zenger, T. (2017). Organization design, proximity, and productivity responses to upward social comparison. Organization Science, 28(1), 1-18.

Palich, L. E., Cardinal, L. B., \& Miller, C. C. (2000). Curvilinearity in the diversification-performance linkage: An examination of over three decades of research. Strategic Management Journal, 21(2), 155-174.

Penrose, E. T. (1959). The theory of the growth of the firm. New York, NY: Wiley.

Porter, M. E. (1985). The competitive advantage: Creating and sustaining superior performance. New York, NY: Free Press.

Posen, H. E., Lee, J., \& Yi, S. (2013). The power of imperfect imitation. Strategic Management Journal, 34(2), 149-164.

Puranam, P., Singh, H., \& Chaudhuri, S. (2009). Integrating acquired capabilities: When structural integration is (un) necessary. Organization Science, 20(2), 313-328.

Puranam, P., Singh, H., \& Zollo, M. (2006). Organizing for innovation: Managing the coordination-autonomy dilemma in technology acquisitions. Academy of Management Journal, 49(2), 263-280. 
Puranam, P., \& Srikanth, K. (2007). What they know vs. what they do: How acquirers leverage technology acquisitions. Strategic Management Journal, 28(8), 805-825.

Qian, L., Agarwal, R., \& Hoetker, G. (2012). Configuration of value chain activities: The effect of pre-entry capabilities, transaction hazards, and industry evolution on decisions to internalize. Organization Science, 23(5), $1330-1349$.

Rawley, E. (2010). Diversification, coordination costs, and organizational rigidity: Evidence from microdata. Strategic Management Journal, 31(8), 873-891.

Rawley, E., \& Simcoe, T. S. (2010). Diversification, diseconomies of scope, and vertical contracting: Evidence from the taxicab industry. Management Science, 56(9), 1534-1550.

Riordan, M. H., \& Williamson, O. E. (1985). Asset specificity and economic organization. International Journal of Industrial Organization, 3(4), 365-378.

Rivkin, J. W. (2000). Imitation of complex strategies. Management Science, 46(6), 824-844.

Rivkin, J. W. (2001). Reproducing knowledge: Replication without imitation at moderate complexity. Organization Science, 12(3), 274-293.

Rivkin, J. W., \& Siggelkow, N. (2003). Balancing search and stability: Interdependencies among elements of organizational design. Management Science, 49(3), 290-311.

Rivkin, J. W., \& Siggelkow, N. (2007). Patterned interactions in complex systems: Implications for exploration. Management Science, 53(7), 1068-1085.

Rumelt, R. P. (1974). Strategy, structure, and economic performance. Boston, MA: Harvard University Press.

Rumelt, R. P. (1982). Diversification strategy and profitability. Strategic Management Journal, 3(4), 359-369.

Sakhartov, A. V., \& Folta, T. B. (2014). Resource relatedness, redeployability, and firm value. Strategic Management Journal, 35(12), 1781-1797.

Sakhartov, A. V., \& Folta, T. B. (2015). Getting beyond relatedness as a driver of corporate value. Strategic Management Journal, 36(13), 1939-1959.

Shaver, J. M. (2006). A paradox of synergy: Contagion and capacity effects in mergers and acquisitions. Academy of Management Review, 31(4), 962-976.

Siggelkow, N. (2002). Evolution toward fit. Administrative Science Quarterly, 47(1), 125-159.

Siggelkow, N., \& Levinthal, D. A. (2003). Temporarily divide to conquer: Centralized, decentralized, and reintegrated organizational approaches to exploration and adaptation. Organization Science, 14(6), 650-669.

Siggelkow, N., \& Levinthal, D. A. (2005). Escaping real (non-benign) competency traps: Linking the dynamics of organizational structure to the dynamics of search. Strategic Organization, 3(1), 85-115.

Siggelkow, N., \& Rivkin, J. W. (2005). Speed and search: Designing organizations for turbulence and complexity. Organization Science, 16(2), 101-122.

Siggelkow, N., \& Rivkin, J. W. (2006). When exploration backfires: Unintended consequences of multilevel organizational search. Academy of Management Journal, 49(4), 779-795.

Simon, H. A. (1947). Administrative behavior. New York, NY: Macmillan.

Sorenson, O. (2003). Interdependence and adaptability: Organizational learning and the long-term effect of integration. Management Science, 49(4), 446-463.

Teece, D. J. (1980). Economies of scope and the scope of the enterprise. Journal of Economic Behavior \& Organization, 1(3), 223-247.

Teece, D. J. (1982). Towards an economic theory of the multiproduct firm. Journal of Economic Behavior \& Organization, 3(1), 39-63.

Teece, D. J. (2007). Explicating dynamic capabilities: The nature and microfoundations of (sustainable) enterprise performance. Strategic Management Journal, 28(13), 1319-1350.

Thompson, J. D. (1967). Organizations in action: Social science bases of administrative theory. New York, NY: McGraw-Hill.

Vidal, E., \& Mitchell, W. (2015). Adding by subtracting: The relationship between performance feedback and resource reconfiguration through divestitures. Organization Science, 26(4), 1101-1118.

Villalonga, B. (2004). Does diversification cause the "diversification discount"? Financial Management, 33(2), 5-27.

Weigelt, C., \& Miller, D. J. (2013). Implications of internal organization structure for firm boundaries. Strategic Management Journal, 34(12), 1411-1434. 
Williams, C. (2007). Transfer in context: Replication and adaptation in knowledge transfer relationships. Strategic Management Journal, 28(9), 867-889.

Williamson, O. E. (1975). Markets and hierarchies, analysis and antitrust implications: A study in the economics of internal organization. New York, NY: Free Press.

Williamson, O. E. (1985). The economic institutions of capitalism: Firms, markets, relational contracting. New York, NY: Free Press.

Williamson, O. E. (1991). Comparative economic organization: The analysis of discrete structural alternatives. Administrative Science Quarterly, 36(2), 269-296.

Winter, S. G. (1995). Four Rs of profitability: Rents, resources, routines, and replication. In C. A. Montgomery (Ed.), Resource-based and evolutionary theories of the firm: Towards a synthesis (pp. 147-178). Norwell, MA: Kluwer Academic Publishers.

Wu, B. (2013). Opportunity costs, industry dynamics, and corporate diversification: Evidence from the cardiovascular medical device industry, 1976-2004. Strategic Management Journal, 34(11), 1265-1287.

Wu, B., Wan, Z., \& Levinthal, D. A. (2014). Complementary assets as pipes and prisms: Innovation incentives and trajectory choices. Strategic Management Journal, 35(9), 1257-1278.

Yao, D. A. (1988). Beyond the reach of the invisible hand: Impediments to economic activity, market failures, and profitability. Strategic Management Journal, 9(S1), 59-70.

Zhou, Y. M. (2011). Synergy, coordination costs, and diversification choices. Strategic Management Journal, 32(6), 624-639.

Zollo, M., \& Winter, S. G. (2002). Deliberate learning and the evolution of dynamic capabilities. Organization Science, 13(3), 339-351.

\section{SUPPORTING INFORMATION}

Additional supporting information may be found online in the Supporting Information section at the end of this article.

How to cite this article: Chen M, Kaul A, Wu B. Adaptation across multiple landscapes: Relatedness, complexity, and the long run effects of coordination in diversified firms. Strat Mgmt J. 2019;40:1791-1821. https://doi.org/10.1002/smj.3060 